\title{
Seismic risk in Turkey, the Aegean and the eastern Mediterranean: the occurrence of large magnitude earthquakes
}

\author{
Paul W. Burton and Robert McGonigle Natural Environment \\ Research Council, British Geological Survey, Murchison House, West Mains Road, \\ Edinburgh EH9 $3 L A$, Scotland
}

Kostas C. Makropoulos Seismological Laboratory, University of Athens, Panepistimiopoli, Athens, Greece

\section{S. Balamir Üçer Kandilli Observatory, Gengelköy, Istanbul, Turkey}

Received 1983 December 29 ; in original form 1982 April 8

Summary. The file of Turkish seismicity developed by Kandilli Observatory, Istanbul, for earthquakes to 1970 is extended here up to 1978 using ISC and PDE data. Entries into this file are maintained on the surface wave magnitude scale $M_{\mathrm{s}}$, and conversion of body wave magnitude $m_{\mathrm{b}}$ to $M_{\mathrm{s}}$ has been carried out where necessary using a formula derived for Turkish earthquakes. Completeness analysis suggests that magnitudes $M_{\mathrm{s}} \geqslant 4.5$ may be used for statistical evaluation of seismic risk. This file is analysed by a range of methods to provide a suite of risk forecasts.

Forecasting results from least squares and maximum likelihood estimates of the whole process Gutenberg-Richter cumulative frequency law of earthquake magnitude occurrence, and from the part process of Gumbel's first extreme value distribution, all show small systematic differences in forecasts, but all three methods lead to magnitude forecasts which fall well within the range of standard deviation. However, these forecasts are obtained by subdividing Turkish seismicity in a cellular manner, and many of these cells show curvature of the earthquake frequency magnitude distribution curve concave with respect to the origin: Gumbel's third asymptotic distribution of extreme values is chosen as an appropriate statistical description. Approximate upper bounds $\omega$ to earthquake surface wave magnitude occurrence are evaluated and estimates of largest magnitudes expected over an interval of $75 \mathrm{yr}$ are forecast with uncertainties. Values of $\omega$ are asymptotic, uncertain, and theoretically correspond to infinite return periods. Strain energy release diagrams are then invoked to estimate empirically the large magnitude $M_{3}$ which is equivalent to the total strain energy which may be accumulated in a region. This equivalent magnitude $M_{3}$ is consistently less than $\omega$ and there is a finite 'waiting time', typically ranging from about 15 to $70 \mathrm{yr}$, during which the energy equivalent to $M_{3}$ may be accumulated. 
Combination of the Gumbel III earthquake occurrence statistics for each cell with an inferred intensity attenuation law leads to a suite of perceptibility curves which give the probability of perceiving specific intensity levels from each possible earthquake magnitude up to the local upper bound magnitude $\omega$. This family of curves generated for an individual cell is seen to be nested, and shows a peak probability for each intensity level which typically occurs at similar magnitudes defined as the 'most perceptible' earthquake. These 'most perceptible' earthquakes show values which range from an $M_{\mathrm{s}}$ of about 5.5 to 7.5 for regional seismicity cells in Turkey; local values may be used as a criterion for choosing engineering design time histories.

The seismic risk parameters from the cellular analysis of seismicity are interpreted as contoured seismic risk maps. These maps show that contoured values of the maximum strain energy earthquake $M_{3}$ usually exceed the $75 \mathrm{yr}$ earthquake by about one-half magnitude for similar geographic locations, but there is overall similarity in contour shape and distribution of highs of seismic risk. When regional variations in attenuation are included for calculations of perceptibility the overall contour shape changes slightly, and the net effect is to emphasize the relative risk associated with the North Anatolian Fault zone. The features of the contoured perceptibility map are compatible with the existing Earthquake Zoning Map of Turkey which is entirely based on observed felt effects in Turkey.

\section{Introduction and methodology}

Turkey is a country of diverse seismicity, ranging from the apparently low to moderate seismicity in southern and central Turkey to the well-known high seismicity of western Turkey and the Anatolian fault system. The problem of assigning return periods of earthquake occurrences is fundamental to all investigations of seismic risk and alternative statistical models will be applied here to an assessment of the rate of Turkish seismicity. The results available at present are open to refinement. Further discussion, comment and no doubt criticism, will help refine our ensuing assessment of seismic risk in Turkey.

The methodology recognizes that 'adequate' earthquake histories or catalogues are vital in the assessment of risk (Burton 1978a) and we have previously compared two separate catalogues describing Turkish and surrounding seismicity since 1900 (Burton et al. 1982). The preferred catalogue, referred to as TURK 70 , is based on the catalogue developed by Kandilli Observatory, Istanbul, and contains many relocations of historical earthquakes. It is extended here, principally by the addition of ISC earthquake data, to 1978.

Alternative statistics of seismicity are applied to the catalogue. The whole process of seismicity occurrence is analysed, using the common Gutenberg. Richter cumulative frequency equation, and in turn compared with the commensurate part process results obtained by Gumbel I extreme value analysis (Epstein \& Lomnitz 1966). The procedure adopted (Burton 1978b, 1979, in principle comparable to Bath 1979a,b) divides the regional seismicity into simple $4^{\circ}$ square cells, so that the analysis technique may be systematically applied, with the modification (Makropoulos 1978) that overlapping cells are cyclically considered in addition to those which are simply adjacent.

Preferred statistics applied to the catalogue are Gumbel's third distribution of extreme values - Gumbel III - which analyse the part process of seismicity occurrence by considering largest annual extreme earthquakes only, again in $4^{\circ}$ cells. The three parameters of Gumbel III are determined for each cell, along with the entire covariance matrix between the 
three parameters. This includes an upper bound to magnitude, but with relatively large uncertainty. Largest earthquake magnitudes which may be expected over a $75 \mathrm{yr}$ interval are then predicted with associated uncertainties. A seismic risk map of the contoured largest expected magnitude over $75 \mathrm{yr}$ is produced as a summary interpretation of the risk throughout Turkey and adjacent areas.

An alternative description of upper bounded and other large magnitude earthquakes is obtained from the time history of strain energy release within each cell of seismicity. Annual strain energy release, converted to an equivalent magnitude value, and the largest transient strain energy release within a cell volume are all determined.

Combination of the preferred Gumbel III description of seismicity with an intensity attenuation law for Turkey leads to intensity perceptibility estimates, i.e. regional probabilities of experiencing particular intensity levels from particular magnitudes of earthquakes, and thereby to possible criteria for choosing engineering design suites of earthquakes on a regional basis. It is necessary to investigate the zoning of Turkey into regions of different seismic attenuation rate to achieve perceptibility calculations with an acceptable degree of validity over the entire region analysed.

The paper demonstrates that as these methods advance - through a linear cumulative frequency law for earthquake occurrence - to incorporate curvature into the frequency law - and finally to take into account regional variations in the rate of seismic attenuation . it achieves a closer approximation to the observed process of seismic risk, including felt and damaging effects.

\section{Turkish earthquake histories and the TURK 78 catalogue}

There is a wealth of historical earthquake data for Turkey. Pinar \& Lahn (1952) provide earthquake locations and damage reports for AD 11 to 1950, and these have subsequently been supplemented with epicentral parameters extending up to 1970 (Ergin, Güçlü \& Uz (EGU) 1964; Ergin, Güçlü \& Aksay 1971). The interval 1904-70 is largely based on instrumental data, held to be reliable, drawn from five major sources: Gutenberg \& Richter (1954), International Seismological Summary, Bulletin Mensuel of the Bureau Central Seismologique International (BCIS), Preliminary Determinations of BCIS, Preliminary Determination of Epicentres of the US Coast and Geodetic Survey (PDE). Alsan, Tezuçan \& Băth (ATB) $(1975,1976)$ used these sources but recomputed epicentres and redetermined magnitudes consistently. Recent extensive contributions to the early seismic history of Turkey include the catalogue of Soysal et al. (1981) for $2100 \mathrm{BC}$ AD 1900, and the work of Ambraseys \& Melville (1982) on Persian earthquake history in general.

For the present statistical assessment we shall use the earthquake catalogue TURK 70 , which has been described by Burton et al. (1982), but extended by eight years to encompass $1900-78$ as TURK 78 . The catalogue TURK 70 consists of merged data, the major contributors being: EGU, ATB, UNS, VKR and MAK; where UNS is the UNESCO Balkan catalogue of Shebalin, Karnik \& Hadžievski (1974), VKR is Karnik's $(1968,1971)$ European catalogue, and MAK (Makropoulos 1978; Makropoulos \& Burton 1981) contains earthquakes in the Aegean and western Turkey relocated using joint epicentre determination techniques. Magnitudes throughout are taken as surface wave type.

The data for 1971-78 to extend TURK 70-78 consist of International Seismological Centre (ISC) and PDE reports which contain many instrumental determinations of magnitude, but often only on the body wave magnitude scale, $m_{\mathrm{b}}$. The surface wave type magnitude $M_{\mathrm{s}}$ is used throughout this study and so a means of conversion from $m_{\mathrm{b}}$ to $M_{\mathrm{s}}$ is required so that all earthquakes with an instrumental magnitude can be incorporated into 


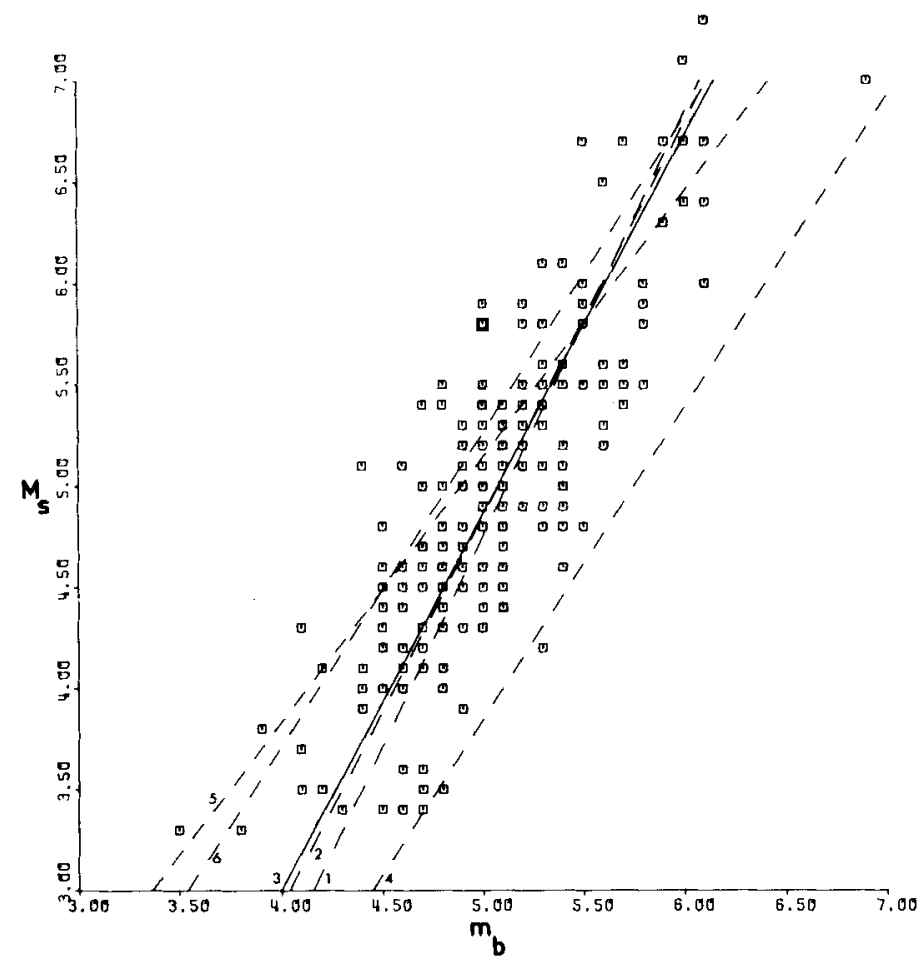

Figure 1. The relationship between the surface wave magnitude $M_{\mathrm{s}}$ and the body wave magnitude $m_{\mathrm{b}}$ for Turkish earthquakes. The square symbols are magnitude data for Turkish earthquakes from the international agencies during 1968-78. Numbered lines correspond to: (1) $M_{\mathrm{s}}=2.08 m_{\mathrm{b}}-5.65$ (Marshall 1970) for global earthquakes, (2) $M_{\mathrm{s}}=1.93 m_{\mathrm{b}}-4.8$ (Marshall 1970) for the Sino-Soviet border, (3) $M_{\mathrm{s}}=1.86 m_{\mathrm{b}}-4.44$ (solid line, this paper) the fit to the plotted magnitude data, (4) $M_{\mathrm{s}}=1.538 m_{\mathrm{b}}-3.846$ (Abe \& Kanamori's 1980, modification of Gutenberg \& Richter 1956) for large global earthquakes, (5) $M_{\mathrm{S}}=1.31 m_{\mathrm{b}}$ (ISC) -1.41 (Makropoulos \& Burton 1981) for Greece, the Aegean and western Turkey, (6) $M_{\mathrm{s}}=1.55 m_{\mathrm{b}}$ (ISC) -2.49 (ATB 1975, 1976) for Turkey.

the catalogue (see Fig. 1). Marshall (1970) observes various relationships between $m_{\mathrm{b}}$ and $M_{\mathrm{s}}$. For the whole world he gives:

$M_{\mathrm{s}}=2.08 m_{\mathrm{b}}-5.65$

using nine months reports from the PDE service and a magnitude range from 4.5 to 7.0 . Using 205 earthquakes for 1966 in the Sino-Soviet border, and the magnitude range 4.0-6.0, (1) is modified by Marshall to

$M_{\mathrm{s}}=1.93 m_{\mathrm{b}} \cdots 4.8$.

The determination of equation (2) assumed errors in both $m_{\mathrm{b}}$ and $M_{\mathrm{s}}$ (McIntyre et al. 1966). Values of both $m_{\mathrm{b}}$ and $M_{\mathrm{s}}$ available from the international agencies for the period 1968-78 are also plotted in Fig. 1, and the third line is the best double-error regression (York 1966) fit to these data as plotted, which with standard errors on the parameters is from 231 events: $M_{\mathrm{s}}=(1.86 \pm 0.02) m_{\mathrm{b}}-4.44 \pm 0.11$.

When the magnitude range is extended to larger events on a global basis then the Abe \& Kanamori (1980) modification of Gutenberg \& Richter's (1956) work might be appropriate, and this leads to

$M_{\mathrm{s}}=1.538 m_{\mathrm{b}}-3.846$ 
which seems to have been determined by least squares with $M_{\mathrm{s}}$ as the independent variable rather than $m_{\mathrm{b}}$. It satisfies Abe \& Kanamori's (1980) data for $M_{\mathrm{s}}$ between 5.2 and 8.7. Makropoulos \& Burton (1981) obtain a regression between $M_{\mathrm{s}}$ and the ISC body wave magnitude $m$ (ISC) for 187 earthquakes during 1964-75 which is

$M_{\mathrm{s}}=1.31 m($ ISC) -1.41

with standard deviation \pm 0.41 on $M_{\mathrm{s}}$. Equation (5) includes data from many earthquakes in the Aegean and western Turkey, and is very similar to the relation derived by ATB (1975, 1976). Their $\bar{M}$, which may be taken for our purposes as $M_{\mathbf{s}}$, and $m$ (ISC), which evaluated from 115 earthquakes is

$\bar{M}=1.55 m($ ISC $) \cdots 2.49$

with standard deviation on $\bar{M}$ of \pm 0.28 . Equation (6) was, of course, determined directly for Turkish earthquakes.

Although equation (4) is appropriate up to great earthquakes, particularly for plate margins of the circum-Pacific, it does not appear appropriate to these data although the Anatolian Fault Zone and part of the Hellenic Arc are included. It is also apparent from Fig. 1 that equations (5) and (6), although representative of the Aegean and western Turkey, are not ideal for the overall region under study here. Marshall's (1970) equations based on a global data set would be an acceptable average conversion; equation (2) developed from earthquakes in the Sino--Soviet border region and from Turkey is very similar to equation (3) developed from the data available here. It is worth noting that these two data sets correspond to different periods of time. Equation (3) was therefore used to convert $m_{\mathrm{b}}$ to $M_{\mathrm{s}}$ values and thus extend the earthquake catalogue to 1978 inclusive. Most $m_{\mathrm{b}}$ conversions were for magnitudes in the middle of the range, the largest not exceeding $m_{\mathrm{b}}=5.6$. It is most unlikely that these magnitudes are affected by multiple mechanisms, which might be the case and cause departures from this conversion formula if larger events were considered.

It is not expected that all magnitude classes are either completely reported or even equally well reported. A modification to Stepp's (1971) method is chosen to specify time intervals for which particular magnitude classes are likely to be completely reported. Completeness has been analysed separately for $23^{\circ}$ to $31^{\circ} \mathrm{E}$ and for $31^{\circ}$ to $48^{\circ} \mathrm{E}$ because it was expected that detection thresholds and reporting of earthquakes would vary significantly between east and west Turkey. For the larger magnitude earthquakes, this does not seem to be the case. Fig. 2(a,b) shows annual histograms of earthquake occurrence and annual frequency, against year, for the five magnitude classes, $1: 4.0 \leqslant M<4.5,2: 4.5 \leqslant M<5.0$, 3: $5.0 \leqslant M<5.5,4: 5.5 \leqslant M<6.0,5: 6.0<M$. Magnitudes greater than 5.0 in Fig. 2 seem mostly complete, incipient incompletness being first suspected for $4.5 \leqslant M<5.0$ in about the first two decades of the catalogue for eastern Turkey. The pattern for magnitudes $4.5 \leqslant M \leqslant 5.0$ shown by bo1h the modified Stepp completeness diagram and the associated histogram indicate variations in seismicity rate. Changes in seismicity rate for large earthquakes over historical sequences of hundreds of years are supported by Ambraseys' (1971) work in Turkey, although there is some disagreement on this issue (Soysal, Kolçak \& Sipahioglu 1982). However, it seems likely that variations on the historical time-scale will not assume great significance over a $79 \mathrm{yr}$ catalogue span, although Soysal et al. also point out that the North Anatolian Fault Zone has been more active in the latter half of the instrumental era than during the first $40 \mathrm{yr}$. Magnitudes below 4.5 are incomplete, although during the last $15 \mathrm{yr}$ of the catalogue (1964 78) the number of detections at these magnitudes increases. The statistical studies of Gençoglu \& Tabban (1973) and Üçer, Ayhan \& Alsan (1976) have considered earthquakes with $M_{\mathrm{s}}$ larger than approximately 4 , thus reducing 

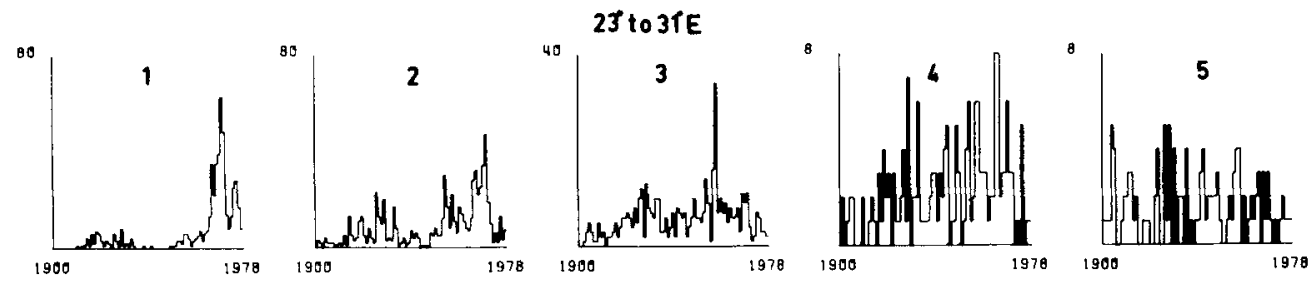

(a)
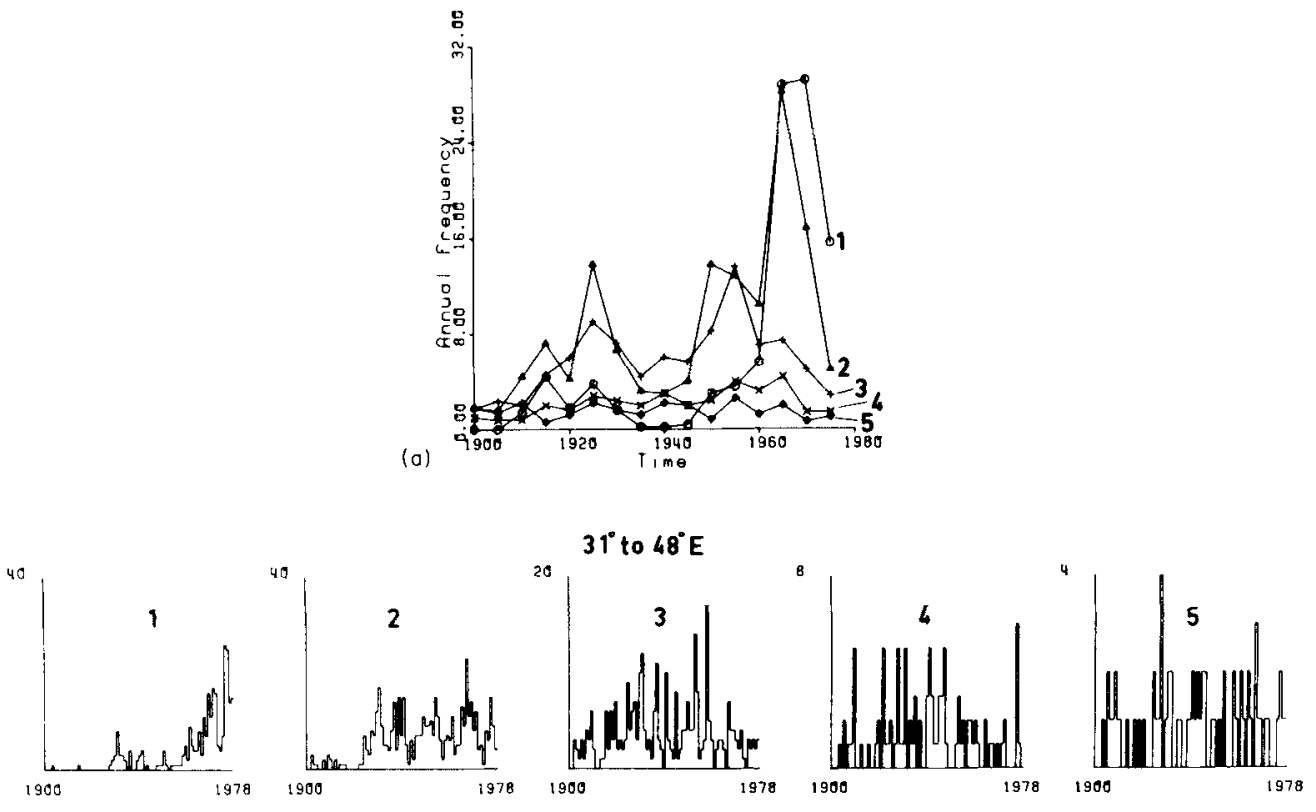

(b)

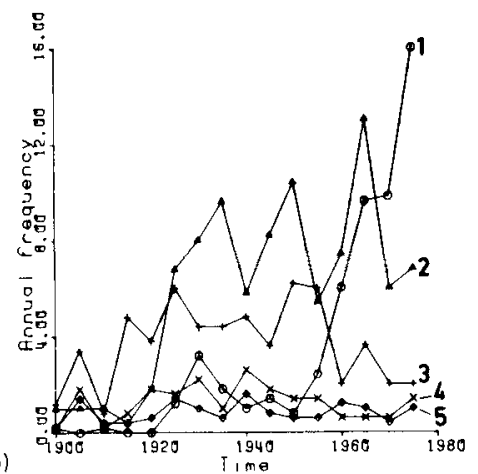

Figure 2. Completeness analysis for magnitudes in the earthquake catalogue TURK 78 for earthquakes in (a) western Turkey, $23^{\circ}$ to $31^{\circ} \mathrm{E}$, and (b) eastern Turkey, $31^{\circ}$ to $48^{\circ} \mathrm{E}$. Histograms represent the number of earthquakes observed each year in the magnitude ranges: (1) $4.0 \leqslant M<4.5$, (2) $4.5 \leqslant M<5.0$, (3) $5.0 \leqslant M<5.5$, (4) $5.5 \leqslant M<6.0$, (5) $6.0 \leqslant M$. The annual frequency of occurrence averaged over $5 \mathrm{yr}$ intervals for each magnitude range is summarized in the graph below the histograms.

major effects of catalogue incompleteness. The ensuing statistical analysis will therefore on balance only use magnitudes $M_{\mathrm{s}} \geqslant 4.5$, and all such entries in TURK 78 are seen in Fig. 3 . The area taken as containing catalogued data acceptable for subsequent analysis is $33-45^{\circ} \mathrm{N}$ and $23-48^{\circ} \mathrm{E}$. 

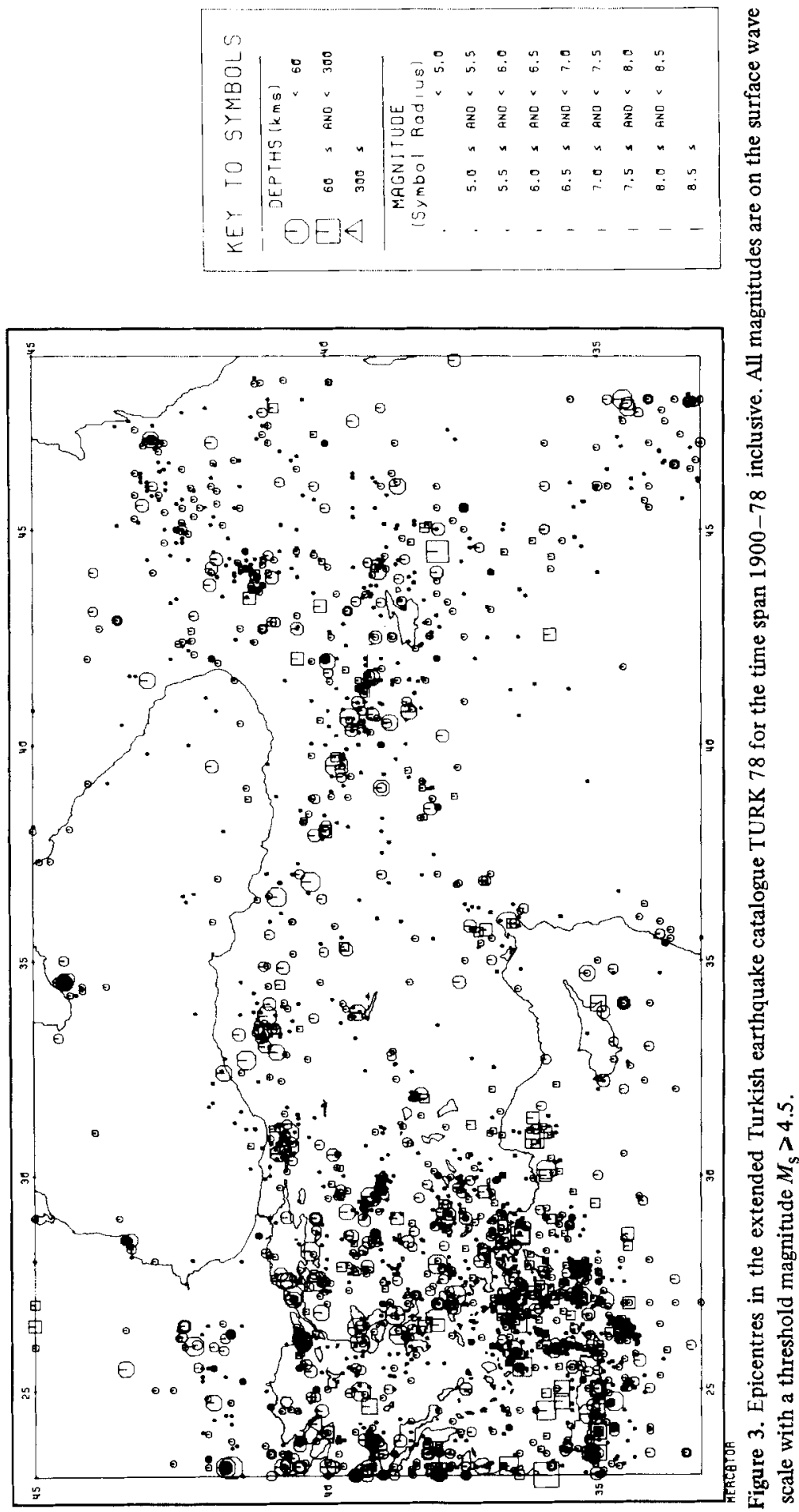


\section{Seismic risk assessments for Turkey}

For these risk assessments of Turkey, alternative statistical treatments will be considered. The completeness analysis of TURK 78 indicates that magnitudes of 4.5 or greater are appropriate for statistical analysis, and this is further substantiated when the Gutenberg-Richter cumulative frequency law is applied below.

There will be no attempt to present all the numerical data here; parameter values are tabulated in the Appendix for those requiring a development of detailed risk estimates at specific localities. Forecasts will be presented as point values and later contoured maps, for $4^{\circ}$ cells on a $1^{\circ}$ grid. However, for illustrative purposes, tabulations of results for $4^{\circ}$ adjacent cells are presented as appropriate. The cell size chosen combines arbitrary convenience with compatability of the documented seismicity and seismic attenuation properties of the region. A $4^{\circ}$ cell sample of seismicity is usually sufficient to provide stable statistical estimates of earthquake magnitude occurrence, smaller cell sizes often do not provide this. Also, when occurrence statistics are subsequently combined with seismic attenuation laws to assess perceptibility, it is important to have an indication of the conditions under which the chosen cell will saturate throughout at a particular intensity level. Intensities of VI are usually only perceived throughout a $4^{\circ}$ cell for magnitude occurrences exceeding $7 \frac{1}{2}$, which is an earthquake exceeding the $75 \mathrm{yr}$ event in almost all the region: a $4^{\circ}$ cell accommodates most significant damaging effects of earthquakes derived from the attenuation laws used later in this paper.

\section{I CUMULATIVE FREQUENCY LAW ASSESSMENT}

The commonest description of earthquake occurrence is perhaps provided by the Gutenberg-Richter cumulative frequency law where the annual number of earthquakes, $N_{\mathrm{c}}$, with magnitude $M$ or greater is given by:

$\log _{10} N_{\mathrm{c}}=a-b M$.

Results obtained by assuming this law applies to TURK 78 are obtained here, but strictly for comparison purposes with the later results assuming a Gumbel III distribution.

Uçer et al. (1976) have considered the years $1900-70$ for $2^{\circ}$ cells $35.5^{\circ}-42.5^{\circ} \mathrm{N}$, $25.5^{\circ} \mathrm{E}-45.5^{\circ} \mathrm{E}$, using equation (7), and obtained values of $a$ and $b$. Two of their observations should be noted. Üçer et al. carried out this analysis excluding aftershocks, and then including aftershocks; the difference they noted fell within the range of observed standard deviations. They also noted, when $\log N_{\mathrm{c}}$ was plotted against $M$, that some cells showed curvature concave towards the origin of the graph, particularly in NE Turkey. This observation foreshadows our later use of Gumbel III.

Three ways of obtaining the two parameters of equation (7) are considered. If the whole process implied by equation (7) is considered, then parameters $a$ and $b$ may be obtained by the usual procedure of least squares, or through the maximum likelihood technique supplied by Aki (1965) and Utsu (1966). More circuitously, the part process of annual extreme magnitudes described by Gumbel's first distribution can be obtained - thus excluding aftershock sequencies - and the parameters $a$ and $b$ of equation (7) deduced in the manner described by Epstein \& Lomnitz (1966). Gumbel I can be expressed in the linear form

$-\ln \left[-\ln G^{\mathrm{I}}(M)\right]=\alpha(M-u)$

where $\alpha$ and $u$ are constants which relate to $a$ and $b$ through

$a=\alpha u / \ln 10$

$b=\alpha / \ln 10$. 
The catalogue TURK 78 has been taken to cover the area of $33-45^{\circ} \mathrm{N}, 23-48^{\circ} \mathrm{E}$. This area is divided into $4^{\circ}$ cells, the first being $33-37^{\circ} \mathrm{N}, 2327^{\circ} \mathrm{E}$, centred on $35^{\circ} \mathrm{N}, 25^{\circ} \mathrm{E}$. Parameters and forecasts ensuring from equation (7) are thus considered to correspond to this point. The cell may then be moved eastwards by $1^{\circ}$ etc., thus developing an overlapping grid of point values. Such an overlapping grid will therefore generate grid point values at $1^{\circ}$ intervals.

Table 1 lists the parameters obtained for each adjacent $4^{\circ}$ cell obtained from all three approaches. Fig. 4 shows the cumulative magnitude frequency data for all adjacent $4^{\circ}$ cells, and equation (7) fitted to these data using both least squares and maximum likelihood. These two fitted lines are often indistinguishable by eye. We are comparing forecasting ability rather than merely distribution parameters, so the annual expected largest earthquake $M_{1}=a / b$ and the $75 \mathrm{yr}$ earthquake $M_{75}$ are tabulated in Table 1 . A full analysis would include overlapping cells so that more detail of the spatial variation of risk could be mapped, but this is not required here. Băth (1979a) has followed a similar philosophy producing estimates of seismic risk in $2^{\circ}$ cells in Turkey deduced from ATB catalogue with its inherent aspiration to homogeneity.

Inspection of the estimates in Table 1 and the fitted lines in Fig. 4 reveal little difference between the least squares and maximum likelihood approaches. Gumbel I was obtained here by only the least squares approach. All three approaches reveal a consistency of forecast within the standard deviations available, however, the cumulative frequency approach would be grossly influenced by the inclusion of incomplete magnitude data much below $M_{\mathrm{s}} \approx 4.5$. Inclusion of the magnitude cut-off removes the curvature seen at low magnitude and confirms that incompleteness is not a significant phenomenon above magnitude 4.5 .

Table 1. Earthquake occurrence laws using two parameters for each adjacent $4^{\circ}$ cell of seismicity. Values of $a$ and $b$ of the GutenbergRichter cumulative frequency law $\left(\log N_{\mathrm{c}}=a-b M_{\mathrm{s}}\right.$ ) determined by least squares are listed with standard deviations. Where available, standard deviations are printed below the parameter to which they refer. Maximum likelihood estimates of $a$ and $b$ are listed without standard deviations. For these two analyses using the whole process the annual modal earthquake $(a / b)$ and the $75 \mathrm{yr}$ magnitude forecast $M_{75}$ are given. Analysis of the part process using the two parameter annual extreme value distribution of Gumbel I leads to the two parameters, $1 / \alpha$ and mode $u$, and a 75 yr forecast $M_{75}$, all with standard deviations.

\begin{tabular}{|c|c|c|c|c|c|c|c|c|c|c|c|c|}
\hline \multirow{3}{*}{\multicolumn{2}{|c|}{$\begin{array}{c}\text { Cell } \\
\text { lat.long }\end{array}$}} & \multicolumn{6}{|c|}{ Whole process } & \multirow{2}{*}{\multicolumn{2}{|c|}{$\begin{array}{l}\text { Part process } \\
\text { (3) Gumbel I }\end{array}$}} & \multirow{2}{*}{\multicolumn{3}{|c|}{ Forecast }} \\
\hline & & & least squa & & & 21 max llik & & & & & & \\
\hline & & $a$ & $b$ & $a / b$ & $a$ & $b$ & $8 / 6$ & 1.kr & $a$ & 1. & 2 & 3. \\
\hline 35 & 25 & $\begin{array}{l}4.17 \\
0.11\end{array}$ & $\begin{array}{r}-0.76 \\
0.02\end{array}$ & $\begin{array}{l}5.45 \\
0.03\end{array}$ & 3.79 & -0.71 & 5.38 & $\begin{array}{l}0.60 \\
0.05\end{array}$ & $\begin{array}{l}5.27 \\
0.07\end{array}$ & $\begin{array}{l}7.91 \\
0.04\end{array}$ & 8.04 & $\begin{array}{l}7.89 \\
0.18\end{array}$ \\
\hline 35 & 29 & 4.00 & -0.77 & 5.21 & 4.04 & -0.77 & 5.22 & 0.59 & 4,93 & 7.65 & 7.64 & 7.47 \\
\hline 35 & 33 & $\begin{array}{l}0.11 \\
2.98\end{array}$ & $\begin{array}{r}0.02 \\
-0.69\end{array}$ & $\begin{array}{l}0.02 \\
4.32\end{array}$ & 2.49 & -0.60 & 4.14 & $\begin{array}{l}0.06 \\
0.56\end{array}$ & $\begin{array}{l}0.09 \\
4.23\end{array}$ & $\begin{array}{l}0.05 \\
7.03\end{array}$ & 7.27 & $\begin{array}{l}0.21 \\
5.74\end{array}$ \\
\hline 35 & 37 & $\begin{array}{l}0.15 \\
4.26 \\
0.67\end{array}$ & $\begin{array}{r}0.03 \\
-1.04 \\
0.13\end{array}$ & $\begin{array}{l}0.06 \\
4.10 \\
0.26\end{array}$ & 3.39 & -0.87 & 3.90 & & 0.20 & $\begin{array}{l}0.07 \\
5.90\end{array}$ & 6.06 & 0.40 \\
\hline 35 & 41 & $\begin{array}{l}1.29 \\
0.33\end{array}$ & $\begin{array}{r}-0.56 \\
-0.06\end{array}$ & 2.32 & 4.45 & $-1,16$ & 3.84 & & & 5.68 & 5.46 & \\
\hline 35 & 45 & $\begin{array}{l}0.33 \\
4.58\end{array}$ & $\begin{array}{r}0.06 \\
-1.05\end{array}$ & $\begin{array}{l}0.37 \\
4.37\end{array}$ & 5.29 & -1.19 & 4.45 & 0.30 & 4.38 & $\begin{array}{l}0.25 \\
6.16\end{array}$ & 6.02 & 5.69 \\
\hline & & 0.31 & 0.06 & 0.06 & & & & 0.09 & 0.19 & 0.09 & & 0.39 \\
\hline 39 & 25 & $\begin{array}{l}4.56 \\
0.22\end{array}$ & $\begin{array}{r}-0.84 \\
0.04\end{array}$ & $\begin{array}{l}5.43 \\
0.07\end{array}$ & 3.46 & -0.66 & 5.25 & $\begin{array}{l}0.63 \\
0.05\end{array}$ & $\begin{array}{l}5.22 \\
0.08\end{array}$ & $\begin{array}{l}7.66 \\
0.09\end{array}$ & 8.09 & $\begin{array}{l}7.97 \\
0.19\end{array}$ \\
\hline 39 & 29 & $\begin{array}{l}4.12 \\
0.95\end{array}$ & $\begin{array}{r}-0.76 \\
0.01\end{array}$ & $\begin{array}{l}0.07 \\
5.44 \\
0.01\end{array}$ & 4.40 & -0.80 & 5.47 & $\begin{array}{l}0.64 \\
0.05\end{array}$ & $\begin{array}{l}0.00 \\
5.09 \\
0.07\end{array}$ & $\begin{array}{l}7.99 \\
0.02\end{array}$ & 7.80 & $\begin{array}{r}7.17 \\
0.18\end{array}$ \\
\hline 39 & 33 & $\begin{array}{l}3.45 \\
3.35 \\
0.11\end{array}$ & $\begin{array}{r}0.01 \\
-0.74 \\
0.0 ?\end{array}$ & $\begin{array}{l}9.52 \\
0.04\end{array}$ & 3.30 & -0.73 & 4.51 & $\begin{array}{l}0.07 \\
0.62 \\
0.07\end{array}$ & $\begin{array}{l}4.29 \\
0.24\end{array}$ & $\begin{array}{l}0.02 \\
7.07 \\
0.04\end{array}$ & 7.08 & $\begin{array}{l}0.18 \\
6.99 \\
0.31\end{array}$ \\
\hline 39 & 37 & $\begin{array}{l}3.55 \\
0.16\end{array}$ & $\begin{array}{r}-0.76 \\
0.03\end{array}$ & $\begin{array}{l}4.64 \\
0.05\end{array}$ & 3.30 & -0.72 & 4.57 & $\begin{array}{l}0.58 \\
0.07\end{array}$ & $\begin{array}{l}4.49 \\
0.13\end{array}$ & $\begin{array}{l}7.09 \\
0.06\end{array}$ & 7.17 & $\begin{array}{l}7.02 \\
0.28\end{array}$ \\
\hline 39 & 41 & $\begin{array}{l}3.57 \\
0.12\end{array}$ & $\begin{array}{r}-0.72 \\
0.02\end{array}$ & $\begin{array}{l}4.92 \\
0.04\end{array}$ & 3.85 & -0.77 & 5.00 & 0.72 & 4. 54 & 7.51 & 7.43 & 7.65 \\
\hline 39 & 45 & 3.65 & $\begin{array}{r}-0.78 \\
0.02\end{array}$ & $\begin{array}{r}4.69 \\
0.04\end{array}$ & 4.05 & -0.84 & 4.79 & 0.59 & 4.46 & 7.10 & 7.02 & 7.04 \\
\hline 43 & 25 & 2,71 & $\begin{array}{r}-0.61 \\
0.02\end{array}$ & 4.44 & 3.24 & -0.70 & 4.63 & 0.70 & 4.00 & 7.51 & 7.31 & 7.02 \\
\hline 43 & 29 & $\begin{array}{l}4.27 \\
0.39\end{array}$ & $\begin{array}{r}0.02 \\
-1.04 \\
0.07\end{array}$ & $\begin{array}{l}0.06 \\
4.11 \\
0.11\end{array}$ & 3.78 & -0.94 & 4.01 & & & $\begin{array}{l}0.06 \\
5.92 \\
0.11\end{array}$ & 5.99 & \\
\hline 43 & 33 & $\begin{array}{l}3.06 \\
0.10\end{array}$ & $\begin{array}{r}-0.68 \\
-0.08\end{array}$ & $\begin{array}{l}4.52 \\
0.04\end{array}$ & 2.95 & -0.66 & 4.49 & 0.74 & 4.00 & & 7.33 & 7.20 \\
\hline 43 & 37 & $\begin{array}{l}0.10 \\
3.17 \\
0.37\end{array}$ & $\begin{array}{r}0.02 \\
-0.84 \\
0.07\end{array}$ & $\begin{array}{l}0.04 \\
3.76 \\
0.15\end{array}$ & 3.30 & -0.87 & 3.79 & & & $\begin{array}{l}5.04 \\
0.98 \\
0.15\end{array}$ & 5.95 & \\
\hline 43 & 41 & 3.69 & $\begin{array}{r}-0.80 \\
0.04\end{array}$ & $\begin{array}{l}4.21 \\
0.08\end{array}$ & 3.21 & -0.79 & 4.07 & 0.49 & 4.12 & $\begin{array}{l}6.35 \\
0.07\end{array}$ & 6.44 & 6.25 \\
\hline 43 & 45 & $\begin{array}{l}5.06 \\
0.21\end{array}$ & $\begin{array}{r}-1.06 \\
0.04\end{array}$ & $\begin{array}{l}4.78 \\
0.04\end{array}$ & 4.72 & -0.99 & 4.74 & $\begin{array}{l}0.38 \\
0.06\end{array}$ & $\begin{array}{l}4.71 \\
0.10\end{array}$ & $\begin{array}{l}6.55 \\
0.06\end{array}$ & 6.63 & $\begin{array}{l}6.38 \\
0.24\end{array}$ \\
\hline
\end{tabular}




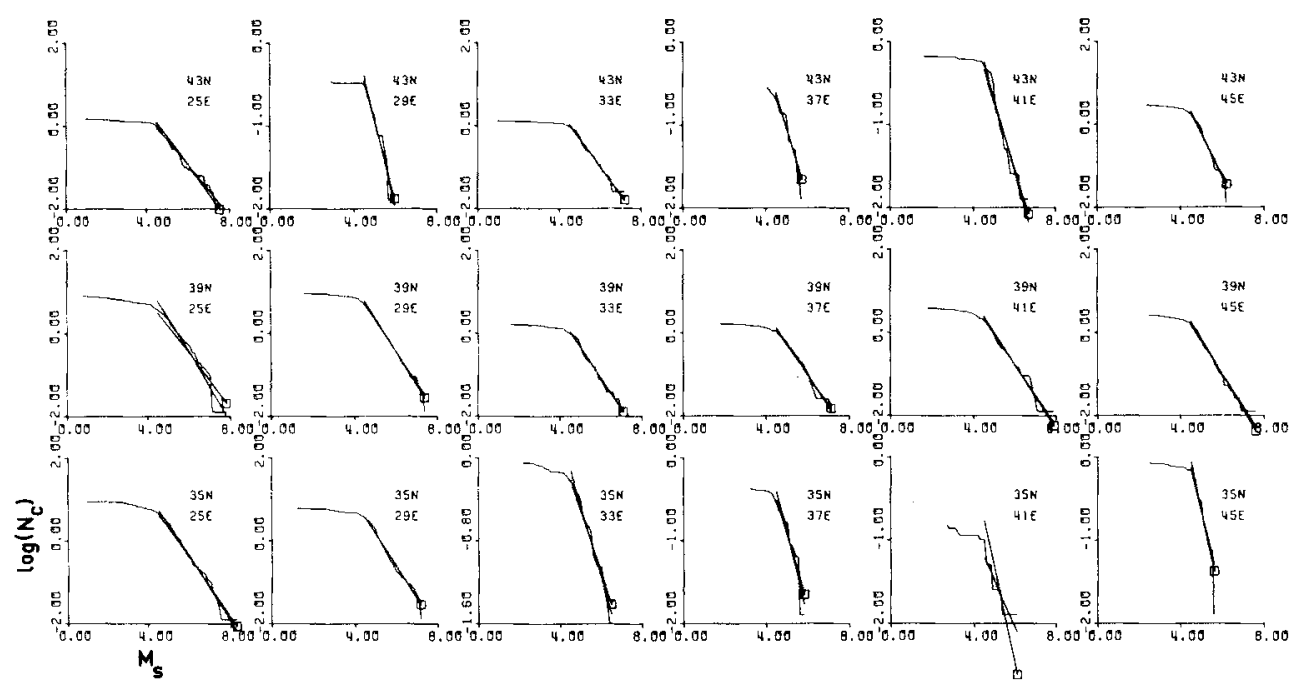

Figure 4. Whole process seismicity statistics using the Gutenberg-Richter law $\log N_{\mathrm{C}}=a-b M_{\mathrm{s}}$. The logarithmic annual cumulative frequency $N_{\mathrm{c}}$ of magnitude larger than $M_{\mathrm{s}}$ is plotted against that magnitude for each adjacent $4^{\circ}$ cell of seismicity. The centre coordinate of each cell is identified in the top right corner of each cell diagram. Two lines are fitted to the data for magnitudes $M_{\mathrm{s}} \geqslant 4.5$. The first line is determined by least squares, whereas the second line (identified by a square symbol) is determined by maximum likelihood: the two lines are often indistinguishable. Corresponding values of $a$ and $b$ and subsequent forecasts are in Table 1.

However, any curvature for the larger, rarer, earthquake magnitude occurrences requires analysis by a quadratic or other law of three implicit parameters.

\subsection{GUMBEL III - EXTREME VALUE STATISTICS}

Gumbel's (1958) theory of extreme values has the advantage that the entire history of earthquake occurrence need not be analysed for probability of earthquake occurrence, instead the earthquake sequence constructed from the largest annual magnitudes is used. Gumbel's third distribution of extreme values - Gumbel III - has been described elsewhere (Yegulalp \& Kuo 1974; Burton 1979) and it is compared here with the above results obtained from other commonly used techniques. Gumbel III is eventually preferred.

The third asymptotic distribution of extremes takes the form

$G^{\mathrm{III}}(M)=\exp \left[-\left(\frac{\omega-M}{\omega-u}\right)^{1 / \lambda}\right]$

where the three parameters are curvature, $\lambda$; an upper bound or magnitude limit, $\omega$; and $u$ is the characteristic value with $G^{\mathrm{III}}(u)=1 / e . G^{\mathrm{III}}(M)$ is the probability that magnitude $M$ is an annual extreme. Methods of estimating Gumbel III parameters have been described by Yegulalp \& Kuo (1974), Makropoulos (1978) and Burton (1979); the latter two are followed here. (Elsewhere, we have found no advantage in applying maximum likelihood to Gumbel III, McGonigle \& Burton 1982.) The three parameters are obtained using a non-linear least squares curve fitting technique based on Levenburg Marquadt, and the resulting matrix equation affords the opportunity to obtain the complete covariance matrix between the 
three parameters, which is of the form:

$\left[\begin{array}{ccc}\sigma_{\omega}^{2} & \sigma_{u \omega}^{2} & \sigma_{\lambda \omega}^{2} \\ \sigma_{\omega u}^{2} & \sigma_{u}^{2} & \sigma_{\lambda u}^{2} \\ \sigma_{\omega \lambda}^{2} & \sigma_{u \lambda}^{2} & \sigma_{\lambda}^{2}\end{array}\right]$

The annual extreme magnitudes $M_{i}(i=1 \ldots n)$ are ranked in ascending size and the 'plotting point' probability at $M_{i}$ is, following Gringorten (1963)

$G^{\mathrm{III}}\left(M_{i}\right)=(i-0.44) /(n+0.12)$.

The technique allows for each individual extreme magnitude to be assigned its own weight. However, because most of the contributions to the catalogue have attempted magnitude homogeneity an uncertainty in magnitude of $\delta M= \pm 0.5$ is assumed throughout. Only annual extremes are considered here, although two or three year extremes could be used. The probability of a particular magnitude not being an annual extreme is $1-G^{\text {III }}(M)$ and the return period $T \mathrm{yr}$ for an earthquake of magnitude $M$ or larger is $1 /\left[1-G^{\mathrm{III}}(M)\right]$. Rearranging equation (10) gives

$M=\omega-(\omega-u) \llbracket-\ln \left[G^{\mathrm{III}}(M)\right] \rrbracket^{\lambda}$.

A largest earthquake with return period $75 \mathrm{yr}$ can be obtained from equation (13), this magnitude will be referred to as $M_{75}$, and confidence bounds on this forecast can be obtained by using either the diagonal elements or the complete covariance matrix. The curvature parameter $\lambda$ is closely correlated with the upper bound and this in turn has a significant influence on the uncertainties in risk estimates forecast using the $75 \mathrm{yr}$ earthquake $M_{75}$. Uncertainties $\sigma_{M}$ on $M_{75}$ are obtained using (Bevington 1969)

$\sigma_{M}^{2} \approx \sigma_{\omega}^{2}\left(\frac{\partial M}{\partial \omega}\right)^{2}+\sigma_{u}^{2}\left(\frac{\partial M}{\partial u}\right)^{2}+\sigma_{\lambda}^{2}\left(\frac{\partial M}{\partial \lambda}\right)^{2}+2 \sigma_{\omega u}\left(\frac{\partial M}{\partial \omega}\right)\left(\frac{\partial M}{\partial u}\right)+\ldots$

Complete results for the three distribution parameters and associated uncertainties for all the overlapping $4^{\circ}$ cells analysed are given in the Appendix. Adjacent cells only are again used as examples, although grid point values are available to scrutiny.

Table 2 lists results of $\omega, u$ and $\lambda$ with their standard deviations for each $4^{\circ}$ cell. Annual extremes have been used in all cases and for the data shown here there were sufficient degrees of freedom to obtain adequate Gumbel III fits to the data. Particularized adjacent cell diagrams showing Gumbel III fitted to these data in adjacent cells are shown in Fig. 5. These cell diagrams have been reduced to linear form by plotting magnitude $M_{\mathrm{s}}$ against the function $\left[-\ln G^{\mathrm{III}}(M)\right]^{\lambda}$ (Burton 1979). The three Gumbel III parameters are determined with differing uncertainties. $u$ and $\omega$ are magnitude equivalents, and estimates of $u$ typically

Table 2. Estimates of Gumbel III parameters $\omega, u$ and $\lambda$, with standard deviations and covariances, for each non-overlapping and adjacent $4^{\circ}$ cell analysed using the earthquake file TURK 78.

\begin{tabular}{|c|c|c|c|c|c|}
\hline Cell & $\omega$ & ${ }_{i s i \omega}$ & $u$ & $\sigma_{U}$ & $\lambda$ \\
\hline $\begin{array}{ll}35 & 25\end{array}$ & 9.26 & 2.11 & 5.27 & 0.08 & 0.19 \\
\hline $35 \quad 29$ & 7.99 & 1.29 & 4.83 & 0.21 & 0.28 \\
\hline & 6.94 & 0.88 & 3.36 & 0.84 & 0.49 \\
\hline $\begin{array}{ll}35 & 45\end{array}$ & 5.77 & 0.83 & 3.38 & 0.79 & 0.50 \\
\hline $39 \quad 25$ & 7.72 & 0.55 & 5.12 & 0.09 & 0.45 \\
\hline $39 \quad 29$ & 8.35 & 1.08 & 5.07 & 0.07 & 0.27 \\
\hline 3933 & 7.73 & 1.63 & 3.98 & 0.33 & 0.29 \\
\hline & 7.35 & 1.12 & 4. 19 & 0.27 & 0.35 \\
\hline 3941 & 8.50 & 1.59 & 4.36 & 0.16 & 0.26 \\
\hline $39 \quad 45$ & 8.13 & 2.12 & 4.32 & 0.19 & 0.23 \\
\hline $43 \quad 25$ & 8.56 & 2.83 & 3.67 & 0.45 & 0.23 \\
\hline $43 \quad 33$ & 7.60 & 1.12 & 2.93 & A. 81 & 0.43 \\
\hline 4341 & 6.68 & 1.58 & 3.61 & 0.88 & 0.36 \\
\hline 4345 & 6.74 & 1.22 & 4.58 & 0.17 & 0.31 \\
\hline
\end{tabular}

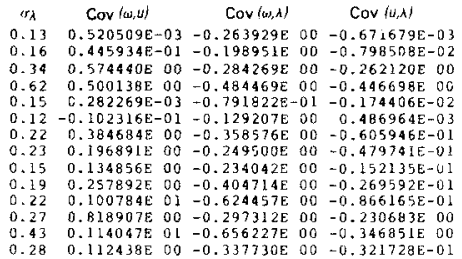



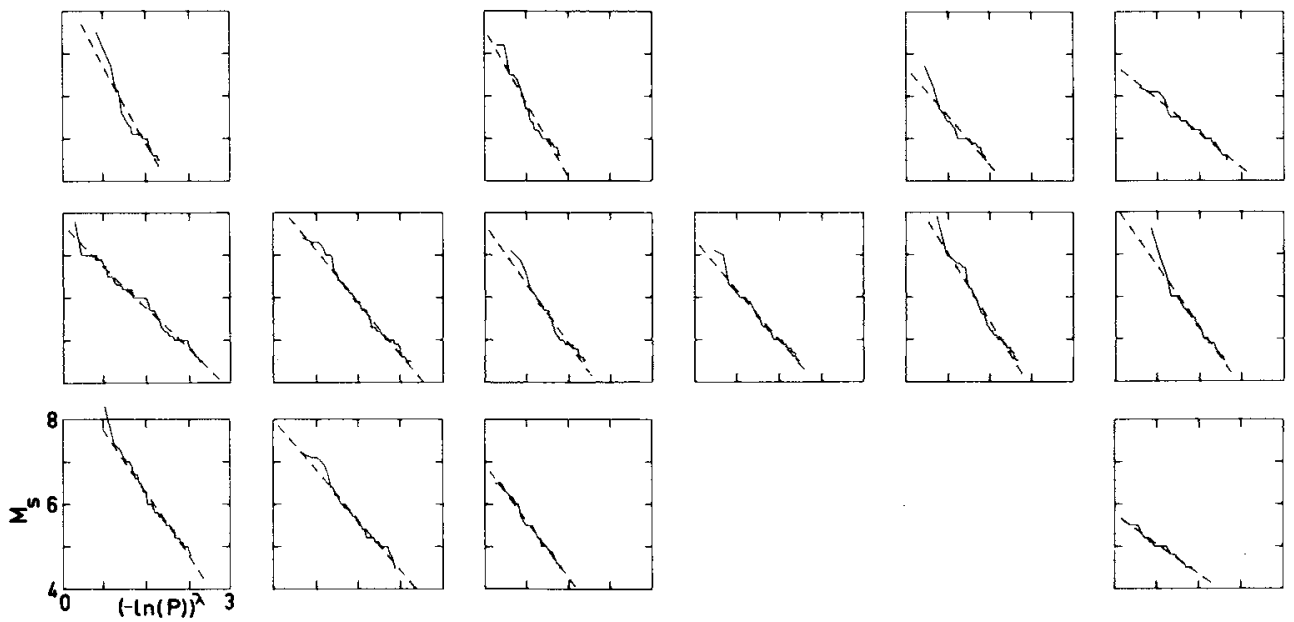

Figure 5. Part process extreme value seismicity statistics using the Gumbel III distribution, where the magnitude $M_{\mathrm{S}}$ is plotted against a function of $P$ (the probability that $M_{\mathrm{s}}$ is an extreme magnitude). Adjacent $4^{\circ}$ cells of seismicity are presented where Gumbel III parameters are obtained, and the cell order is as in Fig. 4. Solid lines represent the data and dotted lines give the fit to the data. For each cell diagram the ordinate $M_{\mathrm{s}}$ extends from 4 to 8 and the abscissa $(-\ln (P))^{\lambda}$ from 0 to 3 . Gumbel III parameters are given in Table 2, and ensuing earthquake forecasts in Table 3.

have standard deviation $\sigma_{u}$ around $0.3-0.4$; estimates of $\omega$ have typical $\sigma_{\omega}$ between 1.0 and 2.0. Grid point values of $\omega$ and the $75 \mathrm{yr}$ forecast $M_{75}$ and all related distribution parameters, including elements of the covariance matrix, are tabulated in the Appendix. Although these grid point values are sufficiently dense for contouring, discussion of this will be deferred

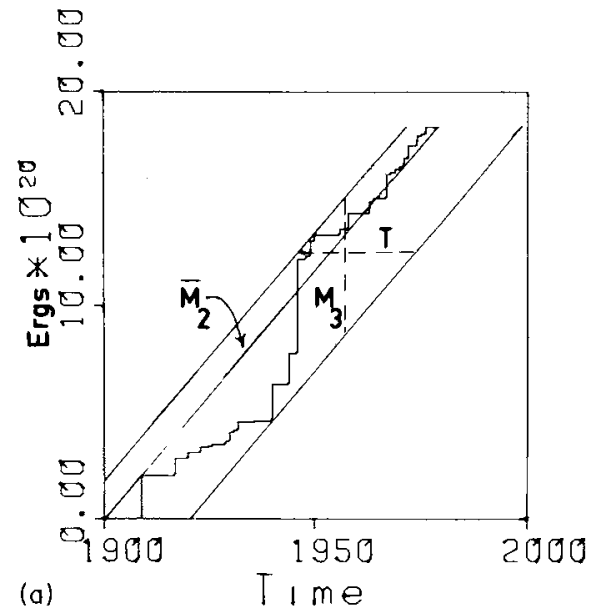

Figure 6. Strain energy release. (a) Schematic of strain energy release showing its cumulative release expressed in ergs deduced from magnitude $M_{\mathrm{s}}$. Annual average strain energy release can be related to an equivalent earthquake magnitude $\bar{M}_{2}$, deduced from the gradient of the middle line which joins the origin to the total strain energy release. Variations in the rate of strain energy release are enveloped by the two outer lines, which are parallel to the middle line. The vertical separation of the enveloping lines may be regarded as a measure of the maximum strain energy release which may be accumulated and released in a region. This is interpreted as the large magnitude earthquake $M_{3}$. Horizontal separation of the enveloping lines is the waiting time $T \mathrm{yr}$, interpreted as the time required for the complete accumulation of strain energy corresponding to $M_{3}$ if no other earthquakes occur meanwhile. (b) Strain energy release diagrams for adjacent $4^{\circ}$ cells of seismicity using the same cell order as Fig. 4 , and the cell diagram format of (a) above. 
Seismic risk in Turkey
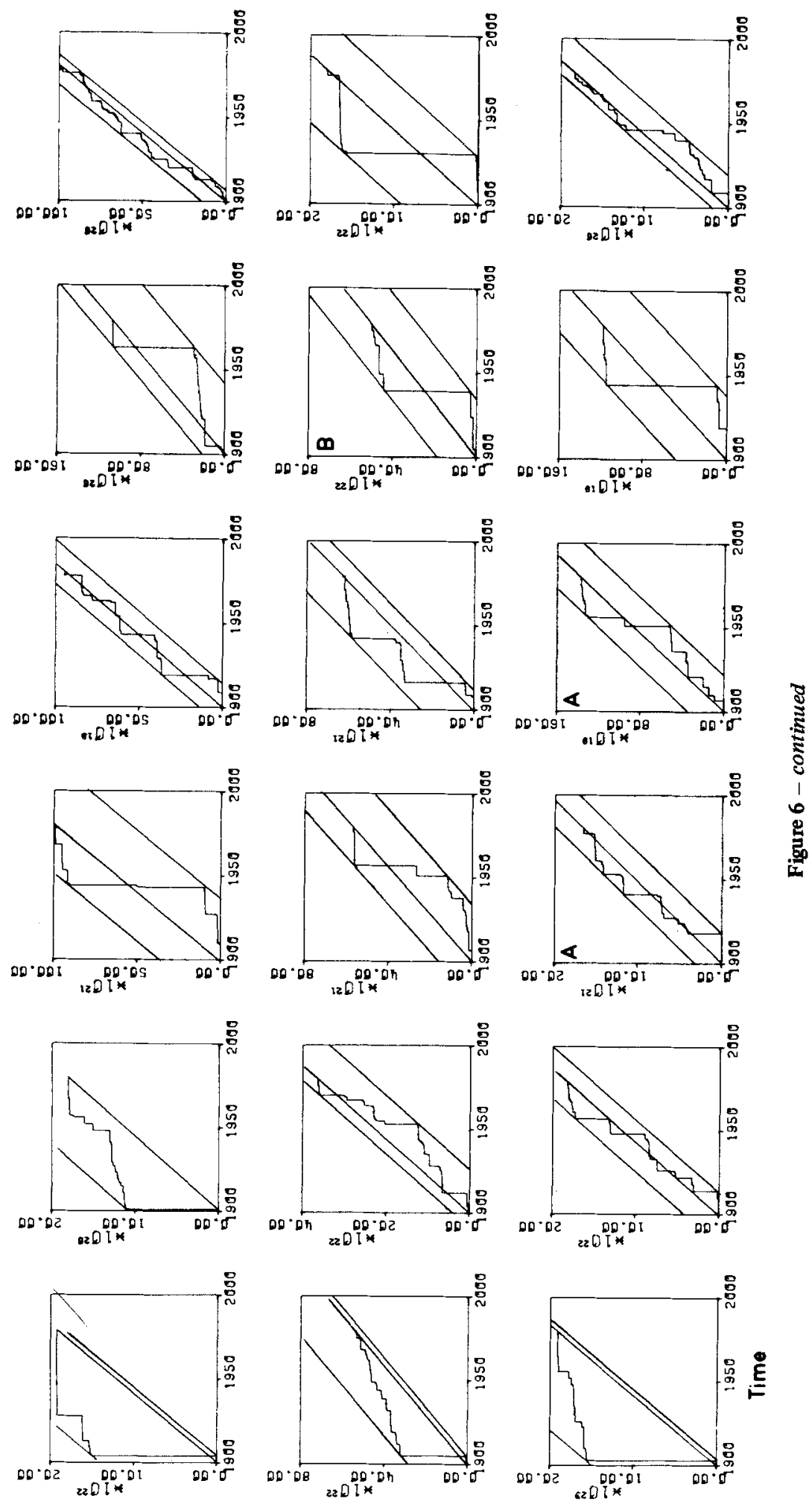

x6дaบz u!edis an!zejnung 
until later when the geometrical grid points will be displaced to positions representative of the seismicity and thereby the seismotectonics.

\subsection{STRAIN ENERGY RELEASE}

A difficulty with the cumulative frequency law of earthquake occurrence is that it extends to infinite magnitudes, unless truncated; on the other hand, although Gumbel III truncates magnitude occurrence, with some uncertainty at the upper bound, this truncation is asymptotic and corresponds to infinite return periods. Neither description seems intuitively ideal when strain energy input mechanisms are considered, which presumably may give rise to a cycle of strain energy input and release with large or upper bounded earthquakes occurring with finite return periods. To investigate this it is necessary to look at actual rates of strain energy release, particularly variations from the mean rate, and relate this to earthquake magnitudes which are thereby characteristic of the seismic risk. This approach is appropriate because it is the rate of strain energy release, and discrepancies from it, which governs seismic risk, rather than individual and isolated occurrences. The seismic energy flux in Turkey has been considered by Üçer et al. (1976) and recently by Båth (1982).

Earthquake magnitude and strain energy release, $E$ erg, can be related through Băth's (1958) equation

$\log E=12.24+1.44 M_{\mathrm{s}}$.

Cumulative strain energy release diagrams are well known, described by Båth (1973), and used by Galanopoulos (1972) and Makropoulos (1978) to discern annual and maximum possible strain accumulation in Greece. The method is easy to apply through graphical means (Fig. 6a). The line joining the origin to the total accumulated strain energy released, and therefore representing the average rate of annual strain energy release, can be expressed as an equivalent magnitude $\bar{M}_{2}$ through equation (15). Lines parallel to $\bar{M}_{2}$ can also be drawn to envelope variations in strain energy release from this mean rate.

The projection of the vertical separation of the two enveloping lines, in ergs, is a measure of the total energy that might be accumulated and released in a region. If this energy was released in one earthquake then it would be the upper bounded earthquake for the region, and its magnitude $M_{3}$ can be assessed through equation (15). The horizontal projection of the enveloping lines represents the minimum time required to accumulate the energy equivalent to $M_{3}$ if no smaller earthquakes occur during this period: this is the waiting time $T$ yr in Fig. 6(a). These values of the large magnitude $M_{3}$ are determined here from a relatively short-term sample of the long-term seismicity, and it is reasonable to expect that an ultimate value of $M_{3}$ will be approached from below as the historical time span! of available data increases. There is evidence from great gap-filling earthquakes (Shimazaki \& Nakata 1980), which individually would constitute a major component of a local $M_{3}$ value, that the size of these great earthquakes can vary from epoch to epoch although the time interval between them may be predictable. However, Soysal et al. (1982) contend that the seismicity data of the last $2000 \mathrm{yr}$ for Turkey, which extends as far as major earthquakes, show no regular or visible periods of seismic activity or quiescence, either in the region as a whole or in separate segments of it.

This concept and presentation is fundamentally different to the foregoing extreme value statistics in that it does not imply a distribution of earthquake magnitude occurrence. It refers to rates of strain energy release which can be equally maintained by a few large earthquakes, or many smaller earthquakes, or a combination of the two. Cumulative strain energy release diagrams for adjacent cells are shown in Fig. 6(b), which reveal possible indications of periodicity in strain energy release, rather than just individual earthquake occurrence. 
Table 3. Comparison of large magnitude occurrence estimated using different processes. Three processes are compared. The earthquake $M_{35} \pm \sigma_{M_{75}}$ and upper bound magnitude $\omega$ are given from the Gumbel III extreme value distribution. The annual strain energy release magnitude $\bar{M}_{2}$, and the maximum strain energy earthquake $M_{3}$ with its waiting time $T$ yr are given from the cumulative strain energy release. The most perceptible earthquake magnitude $M\left(P_{\mathrm{P}} \max \right)$ is obtained from perceptibility. The centroid of each non-overlapping and adjacent $4^{\circ}$ cell of seismicity is obtained by energy weighting the coordinates of each earthquake. All magnitudes are equivalent to the surface wave magnitude $M_{\mathrm{s}}$.

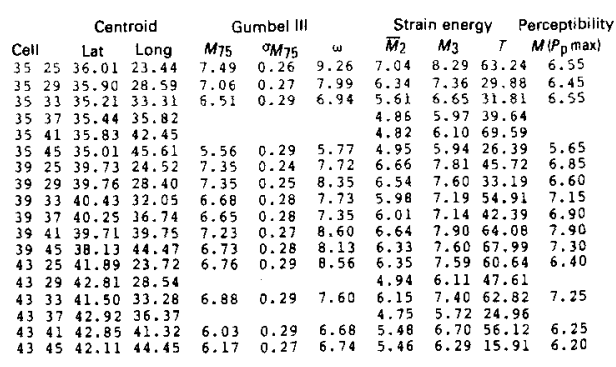

Several cells are characterized by periods which show relative quiescence, activity and quiescence, although the overall activity is usually continual. Cell diagrams $A$ and $B$ in Fig. 6(b) illustrate two apparently contrasting cell types. Cells A show a steady release of strain energy through many moderate sized earthquakes, however, cell B in eastern Anatolia possibly implies a different environment, perhaps akin to the northern central San Andreas zone, where one major earthquake released most of the available strain energy, which has now been apparently re-accumulating in this case since 1939. In each case the overall degree of strain energy release should be taken into account, the release in cell B is orders of magnitude higher than cells $\mathrm{A}$.

Numerical point values of average strain energy release per annum $\vec{M}_{2}$ and $M_{3}$ with the associated waiting time $T$ yr are tabulated for adjacent cells in Table 3 . It is expected that $M_{3}$ and the Gumbel III parameter $\omega$ may bear comparison and this will be discussed later.

\subsection{PERCEPTIBILITY}

The previous sections have generated various estimates of the rate of earthquake occurrence, particularly for large earthquakes; but additionally it is useful to relate those occurrences to the levels of ground motion or vibration with which they are associated. This implies a combination between the statistical earthquake occurrence law, and a law describing the attenuation of ground motion with distance from an epicentre. Attenuation laws may describe ground acceleration or velocity, but until the strong motion programme in Turkey is developed further, intensity attenuation laws will be used which relate directly to damage potential. The method used leads to possible criteria for selection of engineering design suites of earthquake ground motion time histories.

Gumbell III is chosen to represent earthquake probability. $G^{\mathrm{III}}(M)$ is the cumulative probability for extreme values, from this it is easy to calculate the probability density distribution $\phi(M)$ for an earthquake magnitude $M$ occurrence. There will be a set of intensities $I_{i}$ 
associated with a magnitude $M$ occurrence. Within a finite land area the probability $P_{\mathrm{c}}(I)$ of perceiving an intensity $I$ or greater at any point, conditional on $M$, corresponds approximately to the land area fraction within the intensity $I$ isoseismal. Perceptibility, $P_{\mathrm{P}}$, can now be defined as the probability of a magnitude $M$ earthquake occurring and causing perceptible ground motion with intensity at least $I$, that is,

$P_{\mathrm{P}}(I \mid M)=P_{\mathrm{c}}(I) \cdot \phi(M)$.

For small $M$ the $P_{\mathrm{c}}(I)$ tend to zero and, if focal depth is considered, are truncated at zero for occurrences beyond particular depths: hence $P_{\mathrm{p}}$ tends to zero. Similarly, for large $M$ the $\phi(M)$ tend to zero, and for Gumbel III the $\phi(M)$ are truncated at zero for $M \geqslant \omega$ : hence $P_{\mathrm{P}}$ tends to zero. The intermediate maximum $P_{\mathrm{P}}$ defines a suite of most perceptible earthquakes (Burton 1978c) and an explanatory cell diagram of perceptibility is shown in Fig. 7.

\subsubsection{Attenuation}

It is necessary to consider the few attenuation laws available for Turkey before considering variation in perceptibility throughout Turkey. The intensity scales used are either Modified Mercalli (MM) or MSK which have considerable similarities at each degree of the scale.

UNESCO (1976) and Yarar (1977) give expressions relating peak intensity to magnitude, and also for the attenuation of that peak intensity with distance from the epicentre. These equations are attributed to analyses by Ipek, Uz \& Güçlü (1965), Karnik (1971), Gençoğlu \& Tabban (1973), Çaǵpar (1967) and Ipek et al. (1965). These expressions can be reduced to rudimentary attenuation laws linking $M, I$ and epicentral distance $\Delta \mathrm{km}$ :

$I=1.689 M+0.827-3.33 \log \Delta$

$I=2.083 M-0.587-3.33 \log \Delta$

$I=1.718 M+0.795-3.33 \log \Delta$

$I=2.0 M+0.50-3.33 \log \Delta-0.66 \log h$.

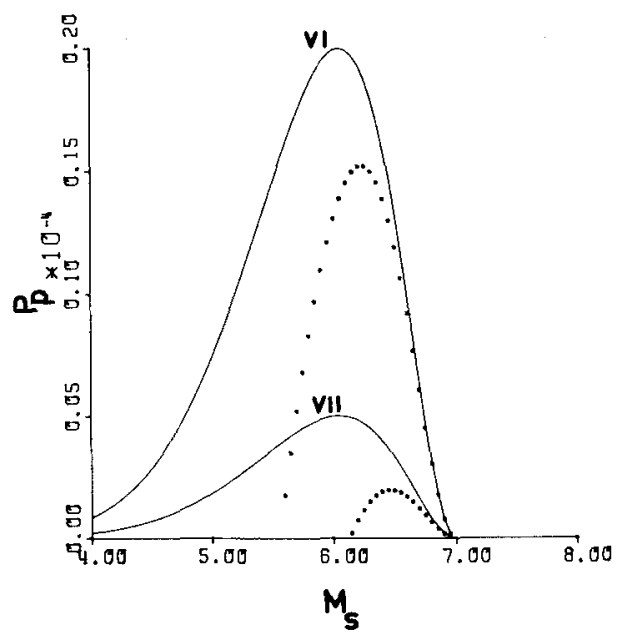

Figure 7. Schematic of perceptibility. Gumbel III earthquake magnitude occurrence laws can be combined with attenuation laws of intensity to estimate the probability $P_{\mathrm{P}}$ of perceiving any intensity level from any earthquake magnitude $M_{\mathrm{s}}$. This schematic shows $P_{\mathrm{P}}$ at intensities VI and VII (assuming specimen values $\omega=7, u=4, \lambda=0.3$ and the attenuation law equation $17 \mathrm{c}$ ) for a notional surface focus carthquake (solid curves). Allowing for a combined focal depth and volume correction (assuming $h^{2}+k^{2}=400$ ) displaces peak perceptibility to higher magnitudes and lower perceptibility values (dotted curves). 
Gürpinar et al. (1979) have examined earthquakes on the North and East Anatolian Fault zone, and estimated attenuation using the MSK intensity scale, both parallel and perpendicular to the surface fault strike. For average isoseismal distance $d_{3} \mathrm{~km}$ from the Anatolian Fault they produce:

$I=2.08 M-4.22-1.05 \ln d_{3}$.

Kolçak \& Sipahioğlu (1979) examined 13 shallow focus earthquakes in Western Anatolia, and suggest a formula using the MM intensity scale of form

$I=1.2372 M+0.1506-0.0332 R+0.00198 M R$

$R=\left(\Delta^{2}+h^{2}\right)^{1 / 2}$

where $h \mathrm{~km}$ is focal depth, $\Delta \mathrm{km}$ is epicentral distance, and $R \mathrm{~km}$ is hypocentral distance.

Ergin (1969) produced no single attenuation law which we might use here, but his results did demonstrate that intensity attenuation is probably zone dependent in Turkey. Equations (17a) to (17f) are plotted in Fig. 8(a) and show this variability for attenuation away from an assumed $M=6.5$ earthquake. As might be expected from the form of the laws 'a' to 'd' all four show excessively high intensities at short focal distances. Distance $\Delta$ may be redefined as $\Delta^{2}=h^{2}+r^{2}+k^{2}: r$ is the epicentral distance, $h$ the focal depth, and $k$ an adjustment factor which allows for finite focal volume thereby eliminating spuriously high epicentral intensities. It is the effect of the double term $h^{2}+k^{2}$ which is vital, and the influence of $h$ or $k$ need not be separated here. The curves of Fig. 8(b) are obtained with $h^{2}+k^{2}$ set to 400 , which may be interpreted as either a notional focal depth of $20 \mathrm{~km}$ with $k=0$ or a 'surface' focus with adjustment factor $k=20$. These curves show that the problem of spuriously high
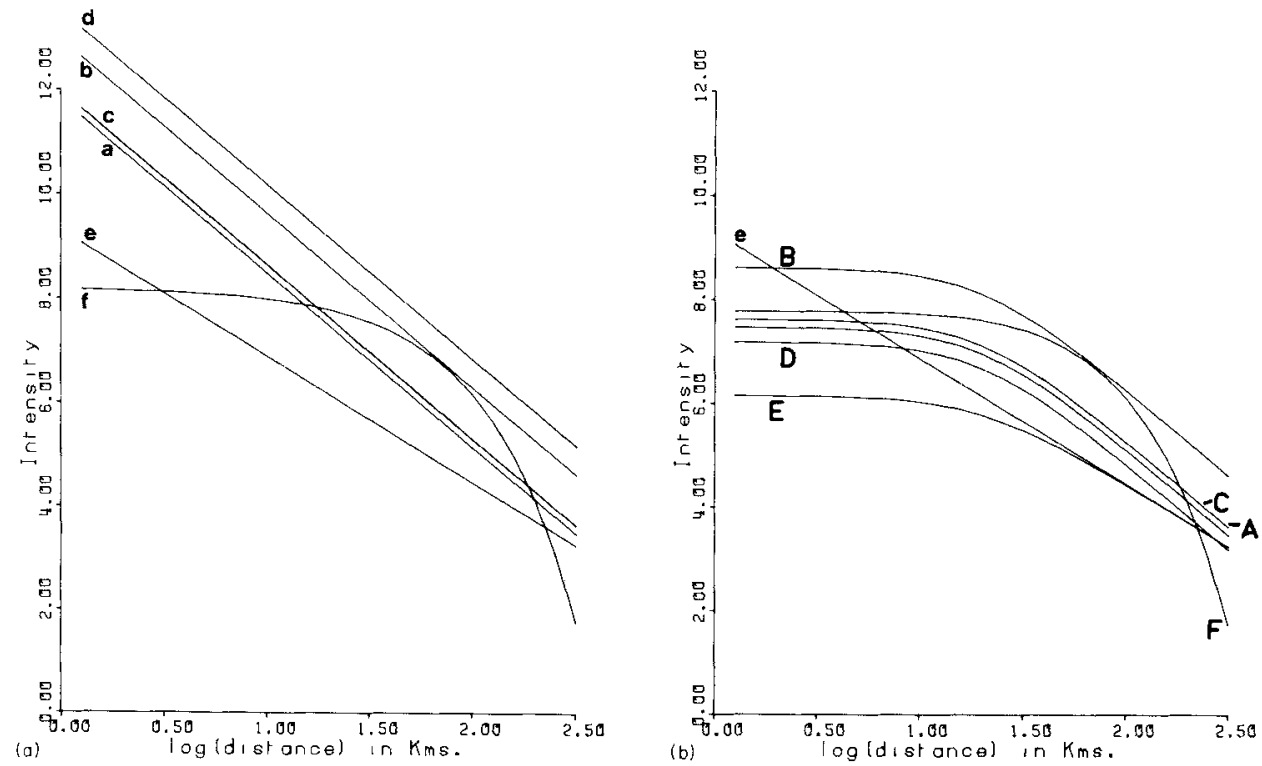

Figure 8. Intensity attenuation laws in Turkey. The six attentuation laws labelled ' $a$ ' to ' $\mathrm{f}$ ' are: a, $I=1.689 M+0.827-3.33 \log \Delta ; b, I=2.083 M-0.587-3.33 \log \Delta ; c, I=1.718 M+0.795-3.33 \log \Delta ;$ $\mathrm{d}, I=2.0 M+0.50-3.33 \log \Delta-0.66 \log h ; \mathrm{e}, I=2.08 M-4.22-1.05 \ln d_{3} ; \mathrm{f}, I=1.2372 M+0.1506-$ $0.0332 R+0.00198 M R$. These symbols and equations are discussed as equations $(17 \mathrm{a}-\mathrm{f})$ in the text. (a) shows the six attenuation laws with no correction for focal depth or focal volume, $h^{2}+k^{2}=0$. (b) includes a joint correction for focal depth and focal volume with $h^{2}+k^{2}=400$ and the modified laws are labelled ' $\mathrm{A}$ ' to ' $\mathrm{F}$ ' respectively; additionally law ' $\mathrm{e}$ ' is repeated but with $h^{2}+k^{2}=0$ and labelled ' $\mathrm{e}$ '. 
epicentral intensities is eliminated, and the apparent $I_{0}$ values correspond more nearly to those implied by the equations cited by Yarar (1977).

Attenuation laws ' $e$ ' and ' $f$ ' are not of precisely the same form as the foregoing. Gurpinar et al.'s law is shown unmodified as 'e' in Fig. 8(b), as well as with $h^{2}+k^{2}=400$ for the modified law, from which it is apparent that correct $I_{0}$ values have been approximated by the unmodified law 'e'. Kolçak \& Sipahioglu's law 'f' was established using shallow earthquakes which they state as a nominal $30 \mathrm{~km}$ depth. Their tabulated earthquake parameters show 13 earthquakes with an average depth of $19.8 \mathrm{~km}$, which is also appropriately modelled by $h^{2}+k^{2}=400$ in Fig. $8($ b): this has only a small effect on the shape of law ' $\mathrm{f}$ '.

To allow in principle for variation in regional attenuation, and to maintain compatibility with observed peak intensities $I_{0}$, the unmodified law 'e' will be used in Northern and Eastern Anatolia, modified law ' $f$ ' in Western Anatolia, and the modified ' $c$ ' elsewhere. This regionalization is shown in Fig. 9 where the use of law ' $\mathrm{e}$ ' is extended slightly southwards in the light of Erdik \& Gürpinar's (1980) use of it in the Kirsehir massif.

These attenuation laws are combined with Gumbel III cell parameters as indicated generally in equation (16) and perceptibility $P_{\mathbf{p}}$ is calculated for each cell. The set of curves for one cell corresponding to a notional surface focus earthquake each give a maximum probability at the same magnitude value for the type of law given in equations $(17 a-f)$. This magnitude, or most perceptible earthquake magnitude, is $M\left(P_{\mathrm{P}} \max \right)$. This maximum for a cell corresponds to that earthquake magnitude which has the highest probability of being perceived at any intensity value, and earthquakes with magnitudes spanning this peak may be regarded as appropriate for engineering design purposes. This simplicity exhibited by the notional surface focus earthquake is slightly modified if corrections for focal volume or depth are incorporated (Fig. 7). Positive values of $h^{2}+k^{2}$ perturb the maximum of the curve corresponding to a particular intensity level in two ways: firstly, the maximum probability

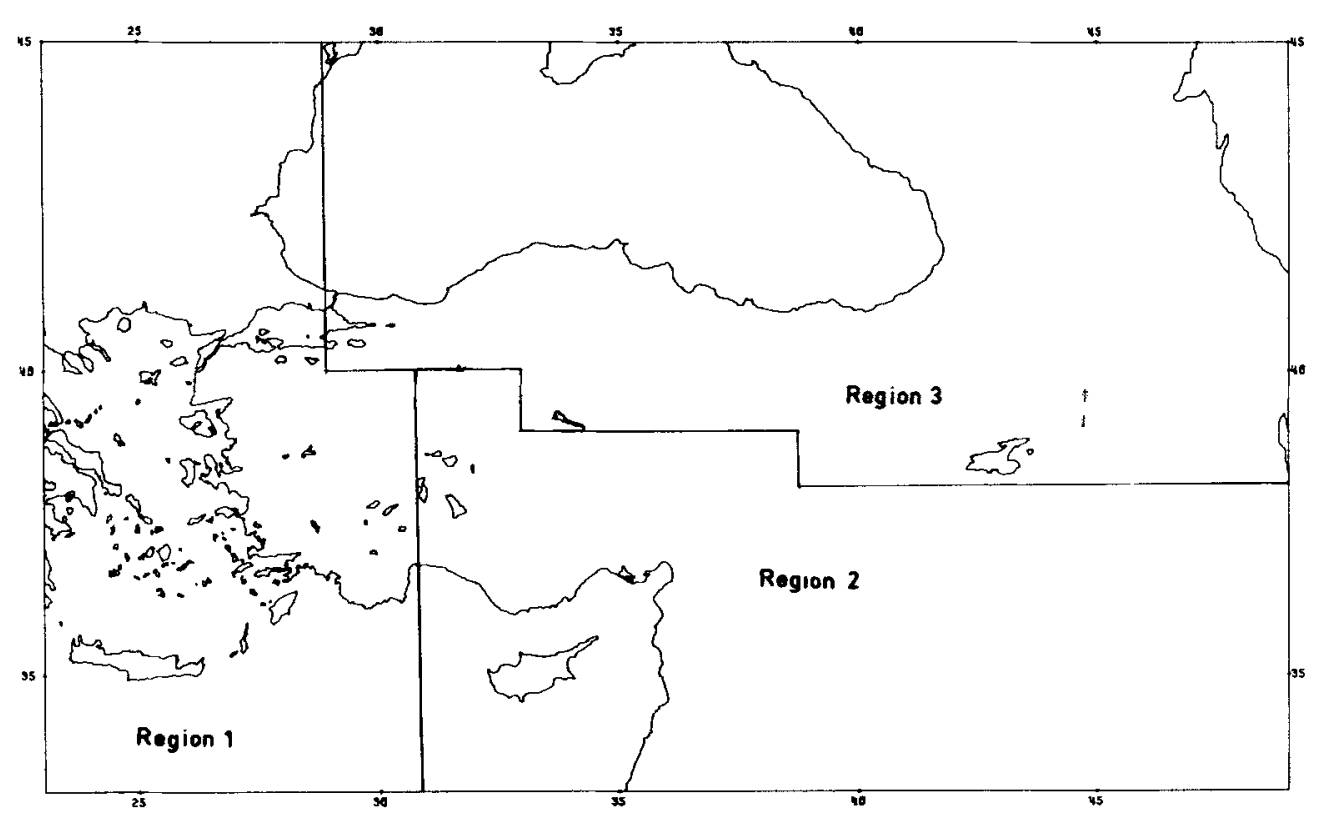

Figuge 9. Regionalization of intensity attenuation laws in Turkey. Region 1: $I=1.2372 M+0.1506-$ $0.0332 R+0.00198 M R$ (equation $17 \mathrm{f}$ modified to include joint focal depth and focal volume correction). Region 2: $I=1.718 M+0.795-3.33 \log \Delta$ (equation $17 \mathrm{c}$ modified to include joint focal depth and focal volume correction). Region $3: I=2.08 M-4.22-1.05$ in $d_{3}$ (equation $17 \mathrm{e}$ ). 
of perceiving a particular intensity is depressed, secondly, the magnitude $M\left(P_{\mathrm{P}} \max \right)$ at intensity $I$ is slightly displaced to higher magnitude values. The attenuation laws used in regions 1 and 2 include a depth correction of the form $h^{2}+k^{2}$ and therefore peak perceptibility magnitudes will be perturbed from the case of zero depth correction. The threshold of significant damage may be taken as intensity VI, and so for consistency the most perceptible earthquake magnitude $M\left(P_{\mathrm{P}} \max \right)$ is selected here from the peak of the intensity VI perceptibility curve for regions 1 and 2 of the attenuation law subdivision of Turkey. In southern Turkey, region 2 of Fig. 9, the attenuation law used does not imply large attenuation and so the corresponding move-out in magnitude from intensities IV to VI takes the small average value of 0.15 . Results for western Turkey, where higher attenuation is implied by the chosen law, contrast with those for southern Turkey leading to an average move-out of 0.45 in magnitude between intensities IV and VI at peak perceptibility. In northern and eastern Anatolia, region 3 of Fig. 9, the attenuation law is not a function of earthquake depth and so magnitude move-out at peak perceptibility does not occur. Ensuing values of $M\left(P_{\mathrm{P}} \max \right)$ for adjacent $4^{\circ}$ cells (see Fig. 10) are given in Table 3 and a complete set of grid point values which will subsequently be contoured are given in the Appendix. These will be discussed later.

\subsection{MAPS OF THE SEISMIC RISK PARAMETERS}

The three quantities chosen here to represent different aspects of seismic risk are $M_{75}, M_{3}$ and $M\left(P_{\mathrm{p}} \max \right)$. These quantities have been determined where possible at the points of $1^{\circ}$ interval grid intersection, each point value being based on a $4^{\circ}$ cell of seismicity centred on the grid point. It is possible to contour these grid point data assuming that seismicity is a random spatial occurrence, but this is clearly not the case, particularly in northern and eastern Anatolia. Alternative approaches could take into account the tectonics of Turkey, the correlation of earthquakes and tectonics expressed as a seismotectonic map, and grid point values of the seismic risk quantities assigned to a precise point on a nearby tectonic feature. However, the correlation of earthquakes and tectonics is not a precise phenomenon throughout Turkey and a different procedure for contouring the seismic risk has been adopted here.

The hypocentre coordinates of each earthquake in each $4^{\circ}$ cell are known, $x_{i}$. The seismicity of a cell may be used to determine a cell centroid, rather than the geographic grid point centre, through

$x=\frac{\Sigma w_{i} x_{i}}{\Sigma w_{i}}$.

Each hypocentre may be weighted, $w_{i}$, and three schemes for doing so were considered. In the first scheme all $w_{i}=1$ and the centroid of hypocentres is obtained, secondly weighting by magnitude with $w_{i}=M_{i}$, thirdly weighting by the energy $E_{i}$ of each earthquake with $w_{i}=E_{i}$.

The first two schemes show no great advantage and there is little to choose between them, whereas weighting by energy is significantly different and moves the centroids close to the larger earthquakes. This last scheme is adopted because it ensures correlation of the seismic risk quantities at the displaced grid points with the larger and damaging earthquakes, and if these earthquakes correlate with known tectonics then this scheme will also achieve a similar measure of seismotectonic validity. The displaced grid points in relation to geographic cell centres are tabulated in the Appendix.

Displaced grid point values of the seismic risk quantities $M_{75}, M_{3}$ and $M\left(P_{\mathrm{p}} \max \right)$ are contoured at quarter magnitude intervals in Figs 11 (Map 1), 12 (Map 2) and 13 (Map 3). 
494
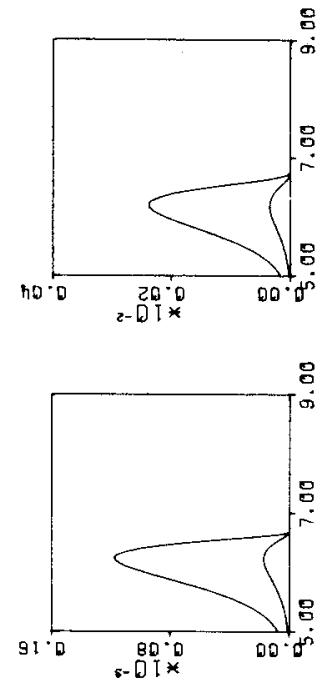

$\frac{m}{\frac{5}{8}}$

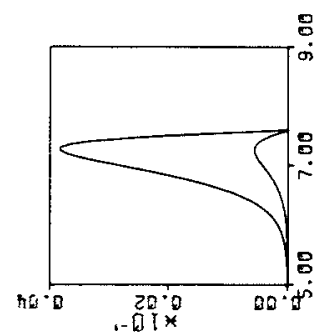

$\overline{\frac{6}{2}}$

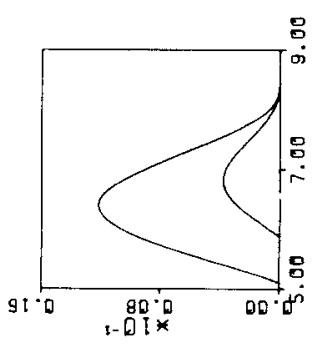

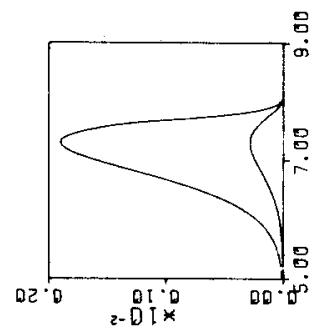
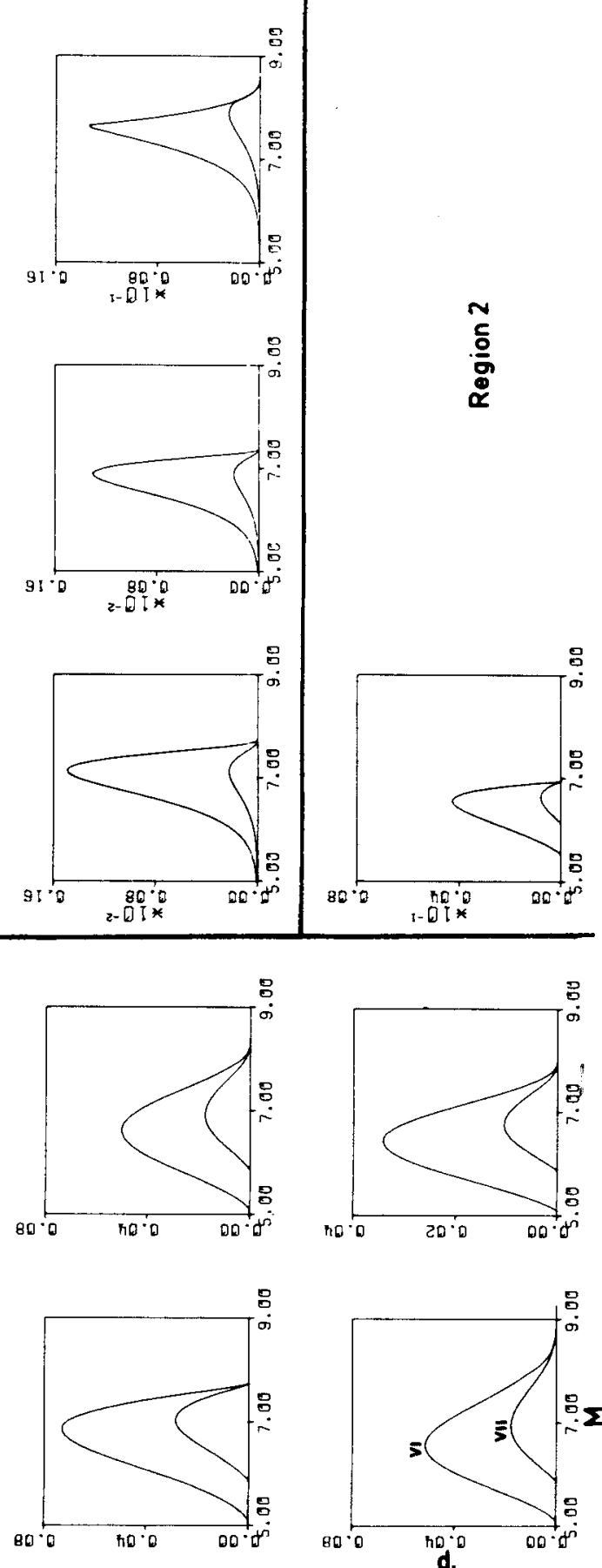

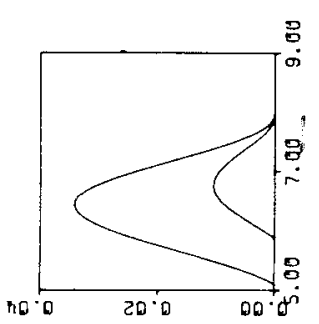

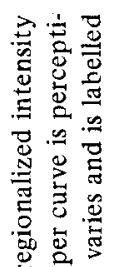

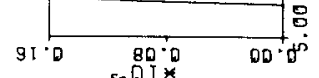

둘

농

莺

诺

$\Xi$

है

8 可

品

in 59

a vi 요

岸总

可丁

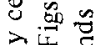

穿

量 0

$=\Sigma$

总鴶急

눙

总导

.

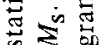

ษั

可

)

焉

定客

동

焉家

政

電嵒

Q

焉范

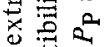

要的

离总总

吉营京

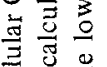

于

주

总点密

를

总雚焉 2 능 용

范定

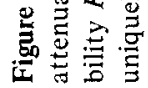


The fundamental results and analysis of seismic risk of this paper are the numerical data tabulated for each geographic and displaced grid point in the Appendix, Tables Al and A2. The overall interpretation of these data are the three maps, Maps 1, 2 and 3.

\subsection{THE MAPS (AND THE SEISMOTECTONICS)}

Before proceeding to the three individual maps of seismic risk it is worthwhile considering the seismotectonics of the region and corresponding broad features on the maps, although for our purpose precise seismotectonic correlations throughout the region are not sought, and anyway are not available.

A simplified concept of continental plate tectonics in the Aegean and Turkey has been given by McKenzie $(1970,1972)$ and discussed in detail by Dewey et al. (1973). The major features of McKenzie's model are widely accepted and include small continental plates moving away from western Iran and eastern Turkey. The landmass south of the North Anatolian Fault and west of the Bitlis zone is the discrete Turkish plate, which is being pushed westward by the Arabian plate which moves relatively northwards. The Bitlis zone reveals compressional tectonics and seismicity that extend from just east of Cyprus northeastwards to a junction with the Anatolian Fault in the western Caucasus. This is in agreement with Nowroozi (1971) who indicates thrust faulting in the Bitlis zone, although there is debate about the precise nature of the process in this region. Allen (1976) suggests that the North Anatolian Fault ends SE of Erzincan intersecting a SW trending conjugate fault system, although this conjugate fault system may be the Abul-Samsar fracture zone of the Caucasus extended south-westwards.

Some earthquakes in eastern Turkey have been the subject of intensive field studies, providing valuable information on seismic risk in terms of damage and ground motion (e.g. Ambraseys \& Zatopek (1968) on the Varto-Ustükiran earthquake, 1966 August 19) and also providing evidence in agreement with the plate tectonic theories. The Liçe earthquake of 1975 September 9 (Yaner \& Blume 1975; Liçe Depremi Raporu 1976; Tezuçan 1979) demonstrates overthrusting faults consistent with compression and Moazami-Goudarzi (1975) points out that there is a long history of seismicity here dating back to AD 995 . At the extremity of our region of interest Ambraseys (1968) stresses the need for investigations into historical seismicity and points out the potential for 'surprise' earthquakes if this is not done, this potential has been recognized elsewhere (Burton 1979) as 'rogue' earthquakes even from limited time histories concerned with primarily instrumented seismicity data. The East Anatolian Fault is recognized by McKenzie as strike-slip, taking up most movement along a $550 \mathrm{~km}$ length between the Arabian and Turkish plates: the primary evidence being Landsat imagery and a left lateral strike-slip attributed to the Bingol earthquake 1971 May 22 (Seymen \& Aydin 1972). Maps 1, 2 and 3 reflect these seismotectonic features in eastern Turkey. Although the North Anatolian Fault is clearly dominant there is a spur of seismicity which may be contoured tenuously corresponding to the East Anatolian Fault; and in terms of seismic risk resolution herein extends through to a relative high in Cyprus. If the East Anatolian Fault takes up the largest part of the motion between the Arabian and Turkish places then its overall seismicity seems surprisingly low in all three maps: perhaps it is an area where seismic creep is dominant, or alternatively, a region where lengthy historical data is required for refining long-term predictions or forecasts.

The North Anatolian Fault zone is the most striking feature of the area, and of all three maps. Its tectonic purpose is to take up right lateral strike-slip motion between the Turkish and Black Sea part of the Eurasian plate. Ketin $(1966,1968)$ describes the tectonic units of Anatolia: the North Anatolian Fault Zone is a few kilometres wide, extends for about 
$1000 \mathrm{~km}$ in northern Turkey, and its seismicity is shallow. Apparent time variations in seismicity on this zone have been noted by Karnik (1969) and discussed since by several authors (Ambraseys 1970; Dewey 1976; Toksöz, Shakal \& Michael 1979; Soysal et al. 1982) and the phenomenon suggested elsewhere in the world (e.g. Grases 1975, for the MiddleAmerican section of the circum Pacific belt). Overall conclusions are not clear: Dewey used a relatively short earthquake time history and concluded that time intervals between successive $M \geqslant 6.0$ 'are not consistent with a constant velocity of source migration'. Toksöz et al. concluded that there was two directional migration away from $39^{\circ} \mathrm{E}$ on the fault zone, with possible seismic gaps at both ends of it. Soysal et al. find no evidence for time variance of the seismicity over the past $2000 \mathrm{yr}$. The seismic risk remains, and whatever its time varying component it has been considered stationary in this paper.

Ketin (1968) has suggested that the North Anatolian Fault may extend into the Aegean Sea; but given even the most recent relocated epicentres of Makropoulos \& Burton (1981) it is not possible to be definitive about its tentative extension into Greece and the detailed tectonics remain unclear. Seismicity in the Marmara Region has been studied by Omote \& Çöloğlu (1971) and Crampin \& Üçcr (1975) suggest that it is here that the North Anatolian Fault splits into three subsidiary lines of seismicity which penetrate western Turkey and the eastern Aegean.

There have been field studies of significant earthquakes in north-western and western Turkey. The Mudurnu earthquake 1967 July 22 (Ambraseys \& Zatopek 1969) revealed $80 \mathrm{~km}$ of surface faulting with right lateral displacement and downthrow to the north, compatible with relatively simple strike-slip motion in the North Anatolian Fault. Maps 1,2 and 3 are consistent with this narrow zone of predominantly strike-slip faulting throughout its length. However, the Gediz earthquake 1970 March 28 in western Turkey shows faulting which is complex and which shrouds the regional tectonics excluding any straightforward tectonic interpretation (Ambraseys \& Tchalenko 1970, 1972; Taşdemiroğlu 1971). About $45 \mathrm{~km}$ of surface faulting was discernible, but Taşdemiroglu points out that the varying senses of fault displacement 'make it difficult to interpret their tectonic significance'. Jackson \& Fitch (1979) after studying aftershocks of the Gediz earthquake (also see Ergin, Uz \& Güçlü 1972) and of Demirci 1969 March 23 in western Turkey formed a general opinion that regional geological structure and surface faulting associated with large earthquakes and their aftershocks are not sufficient to form a tectonic interpretation: the diffuse nature of these tectonics combined with a relatively high seismicity is reflected in Maps 1,2 and 3.

These latter conclusions of Jackson \& Fitch (1979) underline the philosophy on which these seismic risk maps are produced. There have been several attempts to define the seismotectonics of Turkey (e.g. Ketin 1968; Erdik \& Mathur 1977) which have achieved considerable success, yet understanding of the physical processes which underlie the possible seismic sources does not allow these to proceed to estimates of seismic risk with an acceptable precision, although in the long run this is the ideal. In view of this Burton's (1979) regional analysis of seismic risk was made without recourse to tectonic consideration. It emphasized seismicity data as fundamental to risk analysis in itself, and the method is modified here by the introduction of epicentral energy weighting whereby risk parameters are determined at centroids of seismicity. McKenzie (1978, fig. 18) emphasizes the point that faults not visible on Landsat imagery had produced two major shocks since 1928 in the region he was considering. In many cases damaging earthquakes will occur on subterranean faulting with no clear surface faulting interpretation, and seismotectonic correlation will be difficult to achieve satisfactorily. Elsewhere the seismotectonic correlation is clearer as on the North Anatolian Fault. 
The faulting associated with earthquakes during the last seven centuries in Turkey and Greece (Ambraseys 1975, fig. 2) is compatible with the general features of all three risk maps here, and particularly compatible with the perceptibility map (Map 3).

Maps 1, 2 and 3 present different facets of seismic risk:

Map 1 gives the value of the largest surface wave magnitude which may be expected over an interval of $75 \mathrm{yr}$. This is classical seismic risk interpreted from statistical data on the frequency of occurrence of earthquakes, and the predictions or forecasts are not extrapolated wildly beyond the length of the available earthquake history and thereby relate to the contemporary seismic risk.

Map 2 indicates magnitudes associated with maximum strain energy which might be released as single earthquakes throughout the region. The data analysis on which this is founded is similar to methods which attempt to discern seismic gaps (see cell displays of Fig. 6b). It should be noted that contours of $M_{3}$ at specific magnitude levels should contain all epicentres with magnitudes seen in Fig. 3 in excess of that contour level: this acts as an additional constraint on Map 2 and arises because $M_{3}$ must be greater than or equal to the largest earthquake in a region.

Map 3 gives the magnitudes of the most perceptible earthquakes, which are the ones most likely to be felt or cause destruction throughout a region. This is a modification of magnitude occurrence laws (interpreted by Map 1) to include regional variations in the attenuation of seismic energy, and thus emphasize variations in the felt or damaging potential of earthquakes dependent on these two factors.

General differences between these three maps are best illustrated by considering the parameters on which they are based. Consider the values of $M_{75}, M_{3}$ and $M\left(P_{\mathrm{P}} \max \right)$ for the cell centred on $39^{\circ} \mathrm{N}, 45^{\circ} \mathrm{E}$ in eastern Anatolia:

$M_{75}=6.73(0.28)$,

$M_{3}=7.60$,

$M\left(P_{P} \max \right)=7.30$

noting that $\omega=8.13(2.12)$. It is apparent that an $M_{3}$ of 7.6 is less than the upper bound of 8.13 and more than the $M_{75}$ of the Gumbel III $75 \mathrm{yr}$ prediction. These relationships are in keeping with intuitive views of the seismicity process: one would expect the maximum strain energy release earthquake magnitude obtained from a limited time sample (of order $75 \mathrm{yr}$ ) to be intermediate between an asymptotic upper bound and the forecast for the $75 \mathrm{yr}$ extreme. This difference is realized in Maps 1 and 2 as an overall similarity in shape and distribution of the contours, but with the absolute magnitude values of contours in Map 2 exceeding those for similar geographic locations of Map 1, typically by about one-half magnitude. The corresponding value of $M\left(P_{\mathrm{p}} \max \right)=7.3$ is not simply related because it depends on a combination of earthquake frequency of occurrence and intensity attenuation, but it might be taken as appropriate for design guides (selection of suitable strong motion data etc.) in this area.

A noteworthy but somewhat dubious feature of Maps 1 and 2 is the extreme high for these maps in the west Hellenic Arc, which is largely influenced by the one earthquake 1903 August 11 and its magnitude often assessed at about 8 . This very high magnitude is doubtful (Makropoulos 1978) and magnitude about 7 might be more appropriate (Ambraseys 1981), thereby generating a reduced high of risk in this area. However, Wyss \& Baer (1981) suggest this region may be a seismic gap with capability of $M=7.75(0.5)$ during 1980-81. The cell diagram at the lower left of Fig. $6(b)$ shows the strain energy release in this part of the 
Hellenic Arc for this century, and it is consistent with both a region which occasionally produces a large earthquake (as opposed to a steady emission of seismicity) and a region for which the waiting time between large events has almost expired. Similarly, whilst considering the data analysis on which Map 2 is constructed, the cell relevant to the Marmara region (second in the top row of Fig. 6b) shows a similar phenomenon: a large event at the start of this century and littie of great significance since. Both Purcaru \& Berkhemer (1979) and Toksöz et al. (1979) have identified this as a 'seismic gap'.

The major difference amongst the three maps arises when Map 3 is considered. The overall effect of considering regional attenuation is to emphasize the relative risk associated with the Northern Anatolian Fault zone. This is realistic. Contrasted to Maps 1 and 2 the highs on the North Anatolian Fault zone in Map 3 exceed those in the Hellenic Arc. The apparent risk associated with Cyprus is hardly changed by progressing from the first two maps to the third. The low of uncertain seismicity in the Aegean is retained in all three maps, consistent with Galanopoulos (1963). The specific highs at around $31^{\circ} \mathrm{E}$ and $44^{\circ} \mathrm{E}$ are emphasized in relation to risks elsewhere by considering perceptibility. Although these highs are emphasized the features of Map 3 are compatible with the Earthquake Zoning Map of Turkey (Ergunay 1974) which is based entirely on felt effects and macroseismic data.

\section{Conclusions}

Upper bounded, large and damaging earthquakes restrict us by definition to a study of rare events. A capability for statistical forecasting or prediction is vital, as is a commensurate knowledge of uncertainty on the forecasts or predictions. Earthquake catalogues to which statistics are applied also require careful consideration.

The earthquake catalogue used here for Turkey and surrounding areas draws on diverse sources including different original catalogues and different reporting agencies, however, the underlying source material must be similar. The basic earthquake catalogue for Turkey relies heavily on the work of Kandilli Observatory, Istanbul, and the Earthquake Research Institute, Ankara. This has been improved and supplemented for the Aegean and Western Turkey using the relocated epicentres of Makropoulos \& Burton (1981). The surface wave magnitude $M_{\mathrm{s}}$ is used in preference to the more readily available body wave magnitude $m_{\mathrm{b}}$ because it is less likely to saturate for large earthquakes. Few values of $M_{\mathrm{s}}$ are likely to saturate (Kanamori 1977; Abe \& Kanamori 1980) in Turkey in the manner of the great earthquakes of the circum-Pacific belt. Extension in time of the earthquake file from 1971 to 1978 was achieved using ISC and PDE data and required a conversion formula from the readily available $m_{\mathrm{b}}$ to $M_{\mathrm{s}}$. The formula obtained demonstrates that $m_{\mathrm{b}}$ to $M_{\mathrm{s}}$ for Turkey is similar to that derived by Marshall (1970) for the entire world, within the observed magnitude ranges. It is particularly close to Marshall's equation for earthquakes bordering the Sino-Soviet region. Completeness analysis of the ensuing extended file TURK 78 leads to the conclusion that magnitudes of 4.5 or larger are suitable for statistical forecasting, and completeness differences between east and west Turkey although expected were not discerned to any marked degree.

Cellular magnitude data extracted for cells of $4^{\circ}$ side from the seismicity catalogue were fitted first by the two parameters $a$ and $b$ of the traditional Gutenberg-Richter cumulative frequency law. These values of $a$ and $b$ do not need adjustment in the manner described by Utsu (1966) because the $0.1 \mathrm{mag}$ increment used is sufficiently small. Three alternative fitting procedures were applied. Seventy-five year forecasts $M_{75}$ obtained using least squares estimates of the whole process cumulative frequency law are consistently similar to forecasts using maximum likelihood parameters. Forecasts using the part process two parameter distri- 
bution Gumbel I consistently give estimates slightly less than those obtained using the least squares Gutenberg-Richter law. However. all these additional estimates of $M_{75}$ usually lie within the larger standard deviation calculated on $M_{75}$. It is apparent from the cell diagrams illustrating the whole process statistics of Gutenberg-Richter that values of $a$ and $b$ would usually be adversely affected if the completeness analysis was not available.

Cell diagrams which show curvature convex with respect to the origin imply observational roll-off of probability, towards the important rarer magnitudes. This observation can be modelled and analysed using the part process Gumbel III distribution of extreme values, and when this is done it is found that as expected the forecasts of $M_{75}$ using Gumbel 111 are lower than those from Gutenberg-Richter. This is certainly borne out by the summary tables, and results of the Gumbel III parameters for $4^{\circ}$ cells of seismicity are appended for further local studies. The method of analysis also demonstrates that an assessment of uncertainty in the point values of $M_{75}$ can be obtained from the complete covariance matrix obtained between parameters of Gumbel III for one cell; the standard deviation on $M_{75}$ is typically about 0.3 . The covariance matrix includes the large and negative $\sigma_{\omega \lambda}^{2}$ and its use has significantly reduced these forecasting uncertainties.

Forecasts obtained from $4^{\circ}$ cells of seismicity lend themselves to seismic risk mapping. Seismotectonic correlations need not be assumed as the prerequisite to risk mapping. Instead, grid point risk parameters at $4^{\circ}$ cell centres are displaced here to risk mapping coordinates by weighting total earthquake occurrence in a cell to the centroid of strain energy release.

The contoured Map 1 of point values of $M_{75}$ from Gumbel 11 ll shows major variations of seismic risk in Turkey and surrounding areas. These include areas of apparently lower risk in the Aegean and in southern Turkey as well as high risk areas in the Hellenic Arc and in western Turkey extending along the Anatolian Fault into eastern Turkey.

Complete estimation of Gumbel III includes derivation of the parameter $\omega$ which specifies the upper bound to earthquake magnitude occurrence, typically with values of $\sigma_{\omega}$ around one or two magnitudes. It is emphasized that each $\omega$ is only one parameter of a total distribution which is being estimated. It should only be regarded as an uncertain indication of an upper bound.

A further difficulty exists. The process of strain energy release may be quasi-periodic or clustered with apparent periods of relative activity and quiescence, although possessing a maximum to the range of strain energy release. This is compatible with the concept of the upper bound magnitude $\omega$, but not with $\omega$ as an asymptotic upper bound with an implied return period which is theoretically infinite. When values of the magnitude $M_{3}$ equivalent to the maximum strain energy which a cell may release are considered it is concluded that $M_{3}$ is consistently less than $\omega$. On the other hand it is concluded that $M_{3}$ is consistently greater than $M_{75}$. Although $M_{3}$ is consistently greater than $M_{75}$ of Gumbel III it may be close to or less than $M_{75}$ deduced from the Gutenberg--Richter law, emphasizing the conclusion that Gutenberg-- Richter is often inappropriate for forecasts of these rarer earthquake magnitude occurrences. Comparison of contoured $M_{75}$ in Map 1 with contoured $M_{3}$ in Map 2 leads to the conclusion that contours in Map 2 exceed those in Map 1 by about one-half magnitude for the same geographical location.

When perceptibility of earthquake generated strong ground motion is considered it is necessary to combine the chosen frequency of occurrence law with a law of attenuation of strong ground motion away from an epicentre. It is necessary to divide Turkey into three regions which show different attenuation characteristics: western Turkey and the Aegean, Anatolia and eastern Turkey, southern Turkey. The combination of an attenuation law with Gumbel III for earthquake occurrence produces peaked curves of perceptibility of different levels of ground motion. The peak of these curves may be interpreted simply as indicating 
the earthquake magnitude which is most likely to be felt at any level of intensity, and these curves show a range of perceptibility peaks at magnitudes from 5.5 up to 7.5 for $M\left(P_{\mathrm{P}} \max \right)$ throughout Turkey. Standard zoning practise indicates which maximum intensities have occurred in an area, whereas this approach leads directly to the magnitude range which is likely to cause damage within a locality, and which might the refore be adopted as one indicator in the selection of seismic design criteria. When most perceptible earthquakes $M\left(P_{\mathrm{P}} \max \right)$ are contoured in Map 3 significant differences are seen with respect to Maps 1 and 2; particularly the high risk areas on the Anatolian Fault are emphasized at the relative expense of the reduced high of risk in the Hellenic Arc. It is concluded that this map is a realistic interpretation of the risk parameters. It is also significant that the inclusion of attenuation laws in the derivation of seismic risk Map 3 produces contour shapes and a general distribution of highs of risk similar to Ergunay's (1974) Earthquake Zoning Map based solely on macroseismic data. It should be noted that these most perceptible earthquake magnitudes $M\left(P_{\mathrm{P}} \max \right)$ will cause damage at any intensity level in Turkey on more occasions than the higher magnitudes within $M\left(P_{\mathrm{P}} \max \right)<M_{\mathrm{s}} \leqslant \omega$ nearer to $\omega$. In order to improve estimates of perceptibility improved attenuation laws are required for intensity and for other measures of strong ground motion (acceleration and velocity etc.). These could then be integrated to obtain additional seismic risk estimates in terms of ground vibratory parameters (Burton 1981).

\section{Acknowledgments}

We are grateful to Dr Dizer of Kandilli Observatory, Istanbul, and to Professor Drakopoulos of the National Observatory, and the Seismological Laboratory of the University of Athens, for encouraging these cooperative studies.

The work of PWB and RM was supported by the Natural Environment Research Council and is published with the approval of the Director of the British Geological Survey (NERC).

\section{References}

Abe, K. \& Kanamori, H., 1980. Magnitudes of great shallow earthquakes from 1953 to 1977, Tectonophys., 62, $191-203$.

Aki, K., 1965. Maximum likelihood estimate of $b$ in the formula $\log N=a-b M$ and its confidence limits, Bull. Earth. Res. Inst. Tokyo Univ., 43, $237-239$.

Allen, C. R., 1976. Geological criteria for evaluating seismicity, Address as retiring President of the Geological Society of America, 1974 November, Florida.

Alsan, E., Tezuçan, L. \& Băth, M., 1975. An earthquake catalogue for Turkey for the interval 1913-1970, Kandilli Obs., Istanbul, and Seism. Inst., Uppsala, Rep. No. 7-75, $166 \mathrm{pp}$. Also in Tectonophys., 31, T13-T19, 1976.

Ambraseys, N. N., 1968. Early earthquakes in North-Central Iran, Bull. seism. Soc. Am., \$8, 485-496.

Ambraseys, N. N., 1970. Some characteristic features of the Anatolian fault zone, Tectonophys., 9, $143-165$.

Ambraseys, N. N., 1971. Value of historical records of earthquakes, Nature, 232, 375-379.

Ambraseys, N. N., 1975. Studies in historical seismicity and tectonics, in Geodynamics Today, a Review of the Earth's Dynamic Process, pp. 7-16, Royal Society, London.

Ambraseys, N. N., 1981. On the long term seismicity of the Hellenic Arc, Bull. Geofis, teor. appl., 23, $355-359$.

Ambraseys, N. N. \& Melville, C. P., 1982. A History of Persian Earthquakes, Cambridge University Press.

Ambraseys, N. N. \& Tchalenko, J. S., 1970. The Gediz (Turkey) earthquake of March 281970 , Nature, $227,592-593$.

Ambraseys, N. N. \& Tchalenko, J. S., 1972. Seismotectonic aspects of the Gediz, Turkey, earthquake of March 1970, Geophys. J. R. astr. Soc., 36, 229-252.

Ambraseys, N. N. \& Zatopek, A., 1968. The Varto-Üstükiran (Anatolia) earthquake of 19 August, 1964, Bull. seism. Soc. Am., 58, 47-102. 
Ambraseys, N. N. \& Zatopek, A., 1969. The Mudurnu Valley West Anatolia, Turkey, earthquake of 22 July, 1967, Bull. seism. Soc. Am., 59, 521-589.

Băth, M., 1958. The energies of seismic body waves and surface waves, in Contributions in Geophysics, 1, 1-16, eds Benjoff, H., Ewing, M., Howell, B. F. (Jr) \& Press, I., Pergamon Press, London.

Bath, M., 1973. Introduction to Seismology, Birkhauser-Verlag, Basel.

Băth, M., 1979a. Seismic risk in Turkey - a preliminary approach, Tectonophys., 54, T9-T16.

Båth, M., 1979b. Seismic risk in Fennoscandia, Tectonophys., 57, 285-295.

Băth, M., 1982. Seismic energy mapping applied to Turkey, Tectonophys., 82, 69-87.

Bevington, D. R., 1969. Data Reduction and Error Analysis for the Physical Sciences, McGraw-Hill, New York.

Burton, P. W., 1978a. The IGS file of seismic activity and its use for hazard assessment, Seism. Bull. Inst. geol. Sci., No. 6. HMSO, London.

Burton, P. W., 1978b. The application of extreme value statistics to seismic hazard assessment in the European area, Proc. Symp. Anal. Seismicity and on Seismic Risk, Liblice, 1977 October 17-22, pp. 323-334, Academia, Prague.

Burton, P. W., 1978c. Perceptible earthquakes in the United Kingdom, Geophys. J. R. astr. Soc., 54, $475-479$.

Burton, P. W., 1979. Seismic risk in Southern Europe through to India examined using Gumbel's third distribution of extreme values, Geophys. J. R. astr. Soc., 59, 249-280.

Burton, P. W., 1981. Variation in seismic risk parameters in Britain, Proc. 2nd int. Symp. Anal. Seismicity and on Seismic Risk, Liblice, Czechoslovakia, 1981 May 18-23, vol. 2, pp. 495-530, Czechoslovak Academy Sciences.

Burton, P. W., McGonigle, R. W., Makropoulos, K. C. \& Üçer, S. B., 1982. Preliminary studies of seismic risk in Turkey and the occurrence of upper bounded and other large earthquake magnitudes, Multidisciplinary Approach to Earthquake Prediction: Proc. int. Symp. Earthquake Prediction in the North Anatolian Fault Zone, Istanbul, 1980 March 31-April 5, pp. 143-172, eds Mete Isikara, A. \& Vogel, Andreas, Braunschweig, Wiesbaden, Vieweg.

Çaǧpar, A., 1967. Macroseismic investigation on some Anatolian earthquakes (in Turkish), Istanbul Technical University. Jeofysik, 1 (2).

Crampin, S. \& Üçer, S. B., 1975. The seismicity of the Marmara Sea region of Turkey, Geophys. J. R. astr. Soc., 40, 269-288.

Dewey, J. W., 1976. Seismicity of Northern Anatolia, Bull. seism. Soc. Am., 66, 843-868.

Dewey, J. F., Pitman, W. C., Ryan, W. B. F. \& Bonnin, J., 1973. Plate tectonics and the evolution of the Alpine system, Bull. geol. Soc. Am., F4, 3137-3180.

Epstein, B.\& Lomnitz, C., 1966. A model for the occurrence of large earthquakes, Nature, 21 1, 954-956.

Erdik, M. \& Gürpinar, A., 1980. Seismic risk assessment of the Ankara subway system, Safety of Underground Structures, May, Brussels.

Erdik, M. \& Mathur, S. K., 1977. Seismotectonic structure of Turkey, Earthquake Engineering Research Institute, Middle East Technical University, No. 4, June, Ankara.

Ergin, K., 1969. Observed intensity-epicentral distance relations in earthquakes, Bull. seism. Soc. Am., $59,1227-1238$.

Ergin, K., Güçlü, U.\& Aksay, G., 1971. Turkiye dolaylarinin deprem Katologu (1965-1970). [A catalogue of carthquakes of Turkey and the surrounding area (1965-1970)], Istanbul Teknik Universitesi, Maden Fakültesi, Arz Fizigi Enstitüsü, Yayinlari, No. 28.

Ergin, K., Güçlü, U.\& Uz, A., 1964. A catalogue of earthquakes for Turkey and surrounding area (11 AD to 1964 AD), Tech. Univ. Istanbul Fac. Mining Eng., Publ. No. 24.

Ergin, K., Uz, A. \& Güçlï, U., 1972. 28 mart 1970 Gediz depremi art sarsintilarinin incelenmsei (Aftershock study of the Gediz-Turkey earthquake, 28 March 1970), T.C. Istanbul Teknik Universitesi, Maden Fakültesi, Arz Fizigi Enstitüsü, Yayinlari, No. 29.

Ergünay, O., 1974. Earthquake zoning map of Turkey, UNDP-UNESCO survey of seismicity of Balkan region, Symp. Seismic Zoning Map, May, Bucharest.

Galanopoulos, A. G., 1963. On mapping of seismic activity in Greece, Annali Geofis., 16, 37-100.

Galanopoulos, A. G., 1972. Annual and maximum possible strain accumulation in the major area of Greece, Annls géol. Pays Hell., 24, 467-480.

Gençoglu, S. \& Tabban, A., 1973. Statistical analysis of earthquake occurrence in Turkey (1900-1970), Earthquake Statistic and Risk Symp., Balkan Project, 1973 May 26. (Also report on Turkish Republic Ministry of Reconstruction and Resettlement, Earthquake Research Institute, Ankara).

Grases, J. G., 1975. Migration of destructive earthquakes in middle America and associated risk of occurrence, Fifth European Conf. Earthquake Engineering, Istanbul. 
Gringorten, I. I., 1963. A plotting rule for extreme probability paper, J. geophys. Res., 68, 813-814.

Gumbel, E. J., 1958. Statistics of Extremes, Columbia University Press, New York.

Gürpinar, A., Erdik, M., Yüceman, S. \& Oner, M., 1979. Seismic risk analysis of Northern Anatolia based on Intensity attenuation. 2nd US Conf. Earthquake Engineering, Stanford University.

Gutenberg, B. \& Richter, C. F., 1954. Seismicity of the Earth and Associated Phenomena, Princetown University Press. (Facsimile edition, 1965, Hafner, New York.)

Gutenberg, B. \& Richter, C. F., 1956. Magnitude and energy of earthquakes, Annls Géophys., 9, 1-14.

Ipek, M., Uz, A. \& Güçlü, U., 1965. Seismic zones of Turkey based on seismological data (in Turkish), report presented to the meeting for Seismic Codes in Ankara.

Jackson, J. \& Fitch, T. J., 1979. Seismotectonic implications of relocated aftershock sequences in Iran and Turkey, Geophys. J. R. astr. Soc., 57, 209-229.

Kanamori, H., 1977. The energy release in great earthquakes, J. geophys. Res., 82, 2981 -. 2987.

Karnik, V., 1968. Seismicity of the European Area, Part I, Academia, Praha.

Karnik, V., 1969. A comparison of the seismic activity of the seismic zones of Europe, Izv. Earth Phys. $7,70-77$.

Karnik, V., 1971. Seismicity of the European Area, Part II, Academia, Praha.

Ketin, 1., 1966. Tectonic units of Anatolia (Asia Minor), Bull. Miner. Res. Explor. Inst.. Turkey, 66, $23-34$.

Ketin, 1., 1968. Relations between general tectonic features and the main earthquake regions of Turkey, Bull. Miner. Res. Explor. Inst. Turkey, 71, $63-67$.

Kolçak, D. \& Sipahioğlu, S., 1979. Bati Anadulu için geliştirilmiş deprem büyüklüğü - Siddet - Uzaklik iliskisi, Bult. Deprem Arastirma Enstitusu, 23, 28-47 (abstract in English).

Liçe Depremi Raporu, 1976. Report of the Lice earthquake, 6 September 1975 (in Turkish, summary in English), Rep. Earthq. Res. Inst., Ankara.

Makropoulos, K. C., 1978. The statistics of large earthquake magnitude and an evaluation of Greek seismicity, PhD thesis, University of Edinburgh.

Makropoulos, K. C. \& Burton, P. W., 1981. A catalogue of seismicity in Greece and adjacent areas, Geophys, J. R. astr. Soc., 65, $741-762$.

Marshall, P. D., 1970. Aspects of spectral difference between earthquakes and underground explosions, Geophys. J. R. astr. Soc., 20, $397-416$.

McGonigle, R. W. \& Burton, P. W., 1982. Maximum likelihood - an alternative approach to Gumbel III parameter estimation?, Inst. geol. Sci. Glob. Seism. Unit Rep. No. 170.

McIntyre, G. A., Brooks, C., Compston, W. \& Turek, A., 1966. The statistical assessment of Rb-Sr isochrons, J. geophys. Res. 71, 5459-5468.

McKenzie, D. P., 1970. Plate tectonics of the Mediterranean region, Nature. 226, 239-243.

McKenzie, D. P., 1972. Active tectonics of the Mediterranean region, Geophys. J. R. astr. Soc., 30, $109-185$.

McKenzie, D. P., 1978. Active tectonics of the Alpine-Himalayan belt: the Aegean Sea and surrounding regions, Geophys. J. R. astr. Soc., 55, 217-254.

Moazami-Goudarzi, K.. 1975. A preliminary report on the carthquake of 6 th September, 1975 in LiceTurkey, J. Earth Space Phys., 4, 48-67.

Nowroozi, A. A., 1971. Seismo-tectonics of the Persian Plateau, Eastern Turkey, Caucasus, and HinduKush Regions, Bull. seism. Soc. Am., 61,317-341.

Omote, S. \& Cologlu, M. G., 1971. Seismic activity in the Marmara region, Turkey, Bull. int. Inst. Seism. Earthq. Engrg, 5, 17-30.

Pinar, N.\& Lahn, E., 1952. Descriptive catalogue of Turkish earthquakes, in Turkish, Bayindirlik Bakanligi (Ministry of Construction) Publ. Ser. 6, No. 36.

Purcaru, G. \& Berkhemer, H., 1979. Patterns of occurrence of large earthquakes in the region of the Mediterranean, Int. Symp. Earthquake Prediction, April, Paris.

Seymen, I. \& Aydin, A., 1972. The Bingol earthquake fault and its relation to North Anatolian fault zone, Bull. Miner. Res. Explor. Inst., Turkey, 79, 1-8.

Shebalin, N. V., Karnik, V. \& Hadžievski, D. (eds), 1974. Balkan Region - Catalogue of Earthquakes, UNESCO Project Office, Skopje.

Shimazaki, K. \& Nakata, T., 1980. Time-predictable recurrence model for large earthquakes, Geophys. Res. Lett., 7, 279-282.

Soysal, H., Kolf̧ak, D. \& Sipahioğlu, S., 1982. Some aspects of the North Anatolian Fault Zone derived from the comparison of its instrumental data with historical information, Multidisciplinary Approach to Earthquake Prediction: Proc. int. Symp. Earthquake Prediction in the North Anatolian Fault Zone, Istanbul, 1980 March 31--April 5, pp. 223-238, eds Isikara, Mete \& Vogel, Andreas, Braunschweig, Wiesbaden, Vieweg. 
Soysal, H., Sipahioğlu, S., Kolçak, D. \& Altinok, Y., 1981. Historical earthquake catalogue for Turkey and surrounding area, $2100 \mathrm{BC}-1900 \mathrm{AD}$, Scient. Techn. Res. Council Turkey, Proj. No. TBAG 341.

Stepp, J. C., 1971. An investigation of earthquake risk in the Puget Sound area by use of the type I distribution of largest extremes, $P h D$ thesis, Pennsylvania State University.

Taşdemiroğlu, M., 1971. The $1970 \mathrm{Gediz}$ earthquake in Western Anatolia, Turkey, Bull. seism. Soc. Am., 61, 1507-1527.

Tezuçan, L., 1979. Liçe depremi odak mekanizmasi çözümü, Kandilli Rasathanesi Yayinlari, Sismologii Proje No. 2.

Toksöz, M. N., Shakal, A. F.\& Michael, A. J., 1979. Space-time migration of earthquakes along the North Anatolian fault zone and seismic gaps, Pageoph, 117, 1258-1270.

Üçer, S. B., Ayhan, E. \& Alsan, E., 1976. Preliminary statistical results for the preparation of a seismic zoning map of Anatolia, Proc. Seminar Seismic Zoning Map, Skopje, 1975 October 27 - November 4, 1, 225-252, UNESCO project REM/74/009.

UNESCO, 1976. Country monograph of Turkey, Intergovernmental Conf. Assessment and Mitigation of Earthquake Risk, Paris, February 10-19.

Utsu, T., 1966. A statistical significance test of the difference in b-value between two earthquake groups, J. Phys. Earth, 14, 37-40.

Wyss, M. \& Baer, M., 1981. Seismic quiescence in the Western Hellenic Arc may foreshadow large earthquakes, Nature, 289, 785-787.

Yaner, P. I. \& Blume, J. A., 1975. The Liçe, Turkey, earthquake of September 6, 1975: a preliminary engineering investigation, Earthq. Inf. Bull., 8, 4-9.

Yarar, R., 1977. Seismic activities of Turkey and surrounding Balkan region, Bull. int. Inst. Seism. Earthq. Engng, 15, $83-104$.

Yegulalp, T. M. \& Kuo, J. T., 1974. Statistical prediction of the occurrence of maximum magnitude earthquakes, Bull. seism. Soc. Am., 64, $393-414$.

York, D., 1966. Least-squares fitting of a straight line, Can. J. Phys., 44, $1079-1086$.

\section{Appendix: seismic risk parameters}

The main text of this paper describes the several methods of estimating the frequency of

Table A1. The Gumbel III extreme value distribution for all overlapping $4^{\circ}$ cells of seismicity in Turkey. 'Cell' identifies the mid-latitude and longitude of each cell. The three parameters $\omega, u$ and $\lambda$, and the corresponding standard deviations and covariances are listed if they have been obtained.
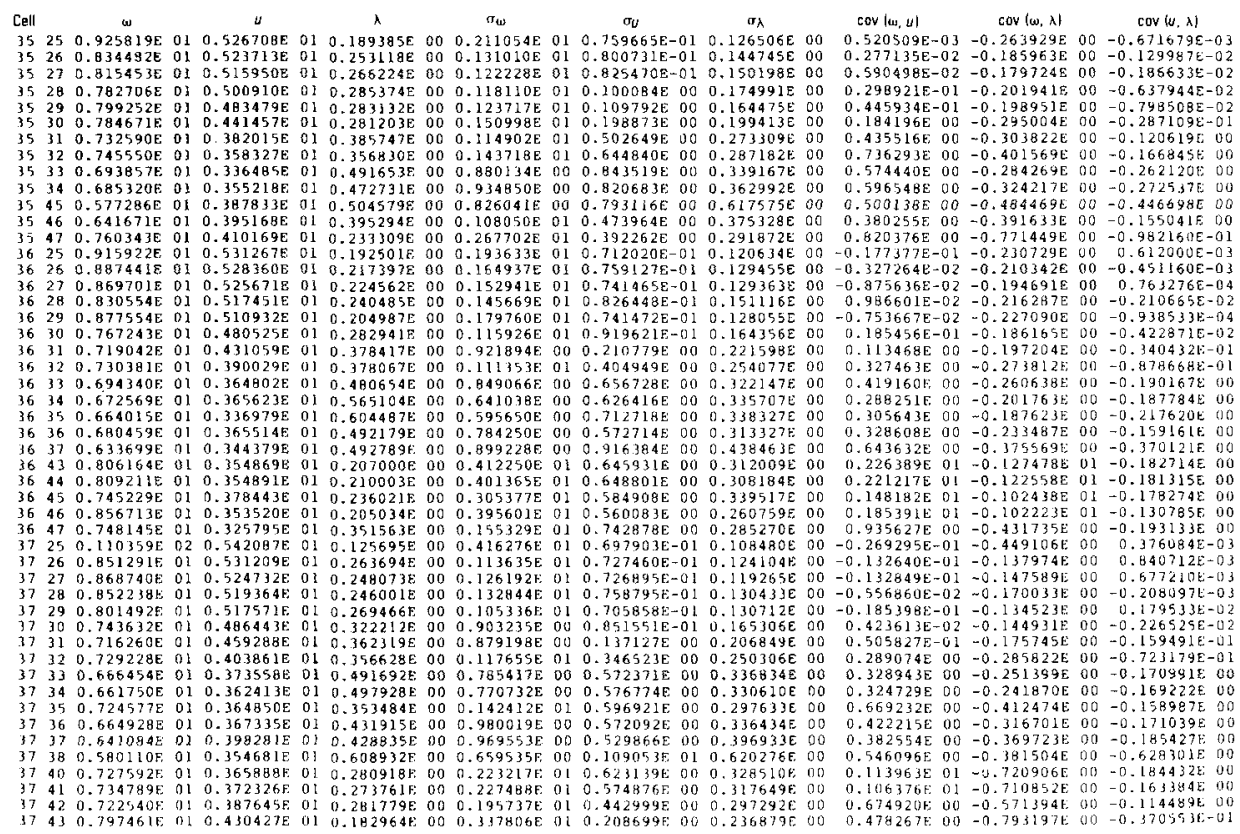
Table 1 - continued

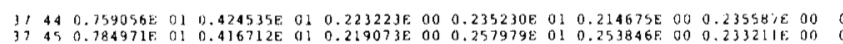

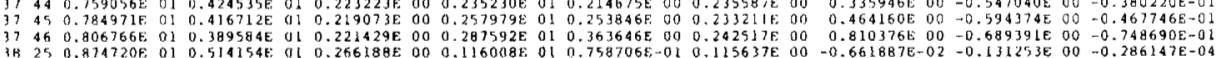

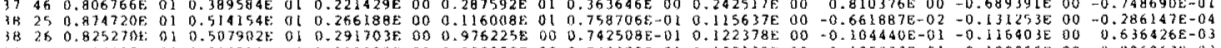

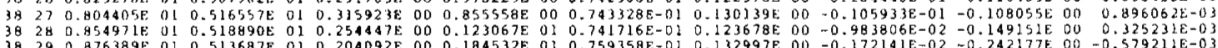

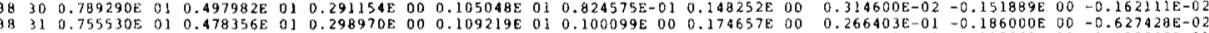

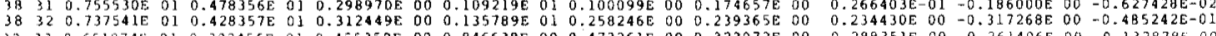

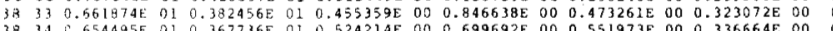

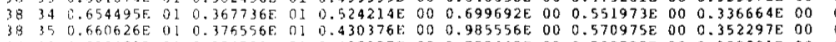

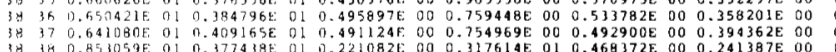

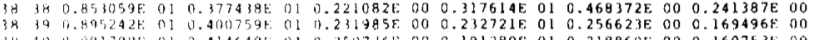

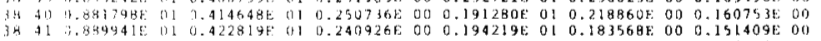

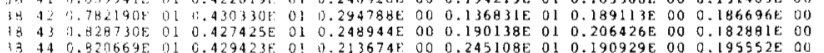

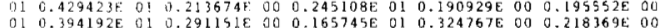

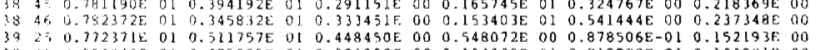

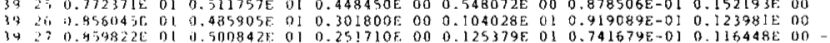

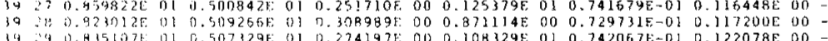

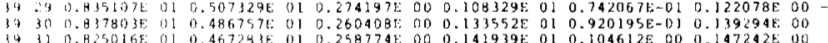

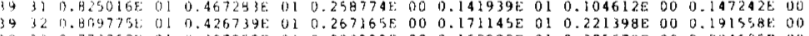

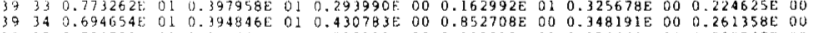

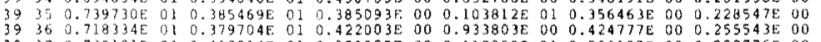

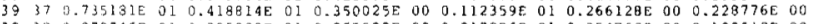

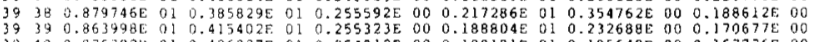

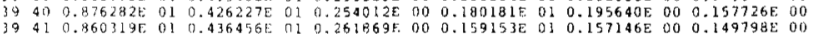

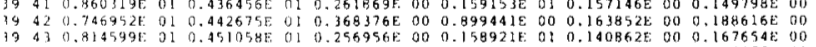

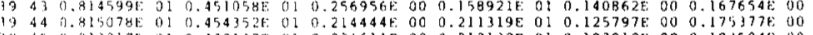

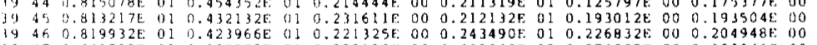

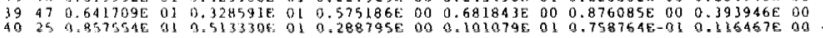

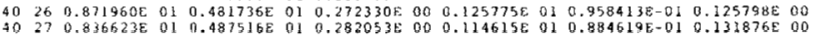

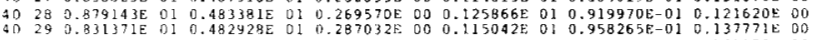

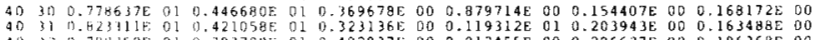

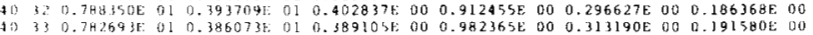

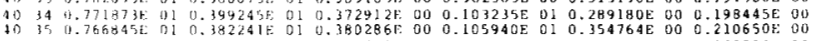

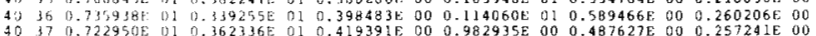

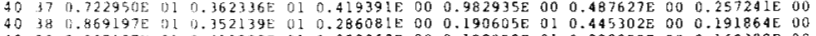

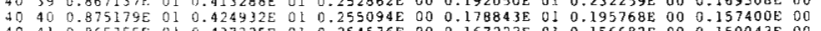

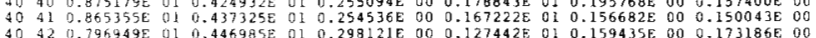

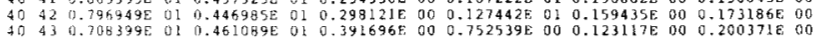

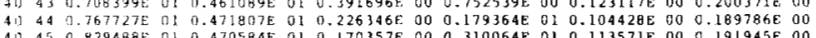

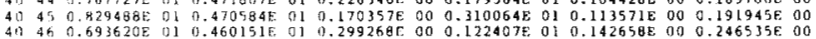

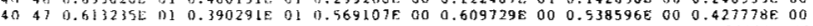

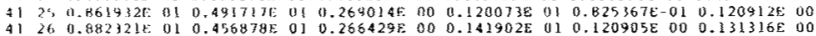

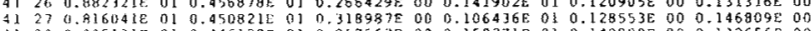

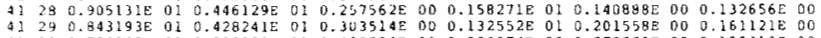

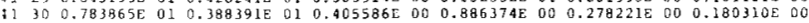

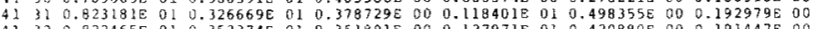

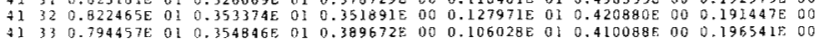

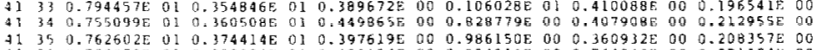

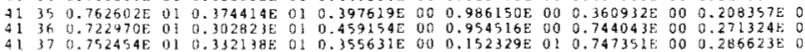

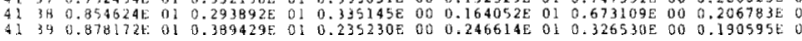

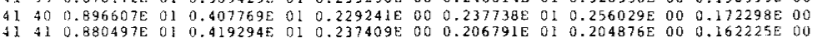

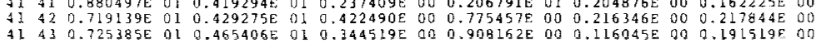

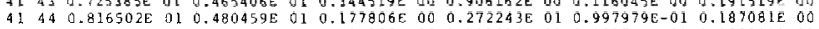
$41 \quad 450.893356 \mathrm{E}$ 01 $0.480787 \mathrm{E}$ ol $0.124355 \mathrm{E}$ 00 $0.511296 \mathrm{E}$ 01 $0.921754 \mathrm{E}-010.185511 \mathrm{E} 00$

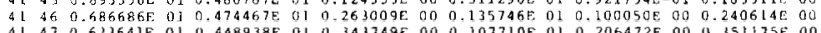

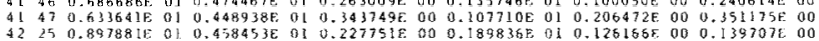

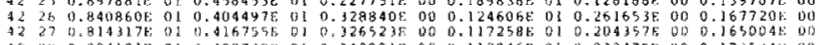

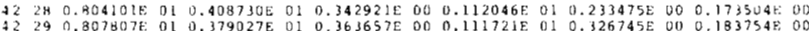

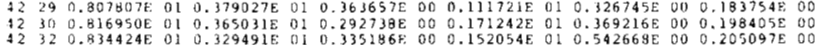

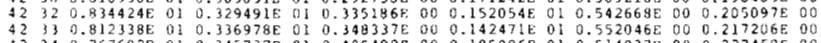

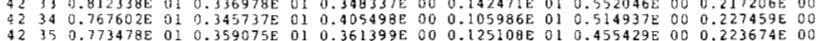

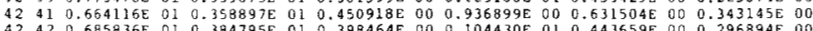

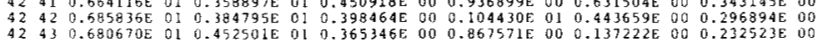

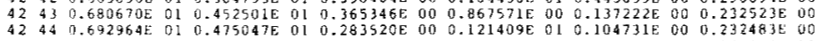

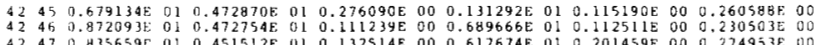

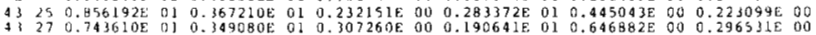

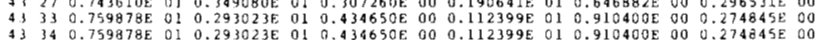

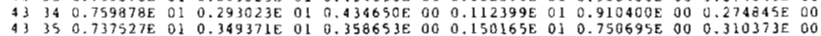

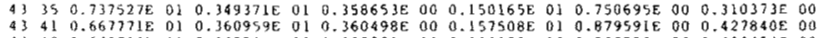

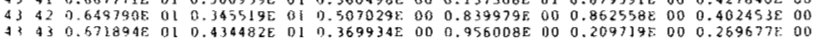

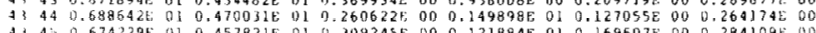

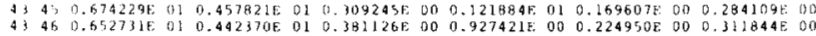

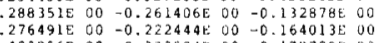

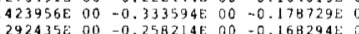
$.265091 \mathrm{E}$ d0 $-0.282742 \mathrm{E}$ 00 $-0.169539 \mathrm{E}$ D

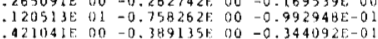
$.274461 E$ DO $-0.302546 E$ U1] $-0.203076 \mathrm{E}-01$ $152750 \mathrm{E}$ DU $-0.249762 \mathrm{E}$ UO $-0.249610 \mathrm{E}-3$

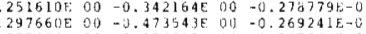

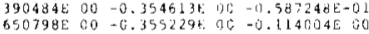
$.2822695-03-0.7918225-01-0.174406 E-52$

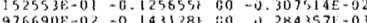

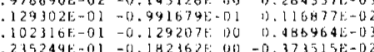

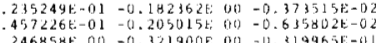

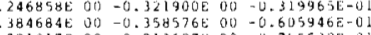
$201817 E$ DO $-0.213627 E$ OO $-0.755532 \mathrm{E}-01$ $.259878 \mathrm{E}$ OU $-0.2229236 \mathrm{E} 00-0.681319 \mathrm{E}-01$ . $96891 \mathrm{E}$ 00 $-0.249500 \mathrm{E} \quad 00-0.479741 \mathrm{E}-(1)$ $\begin{array}{lllll}.582901 \mathrm{E} & 00 & -0.403489 \mathrm{E} & 00 & -0.564334 \mathrm{E}-01 \\ 294503 \mathrm{E} & 00 & -0.316928 \mathrm{E} & 00 & -0.304865 \mathrm{E}-0\end{array}$ $.219366 \mathrm{E}$ O0 $-0.279430 \mathrm{E}$ 00 $-0.223025 \mathrm{E}-01$ $736401 E-01-0.163888 E 00-0.1941905-61$ $110356 \mathrm{E}$ UO $-0.261654 \mathrm{E}$ 00 $-0.141519 \mathrm{E}-0$

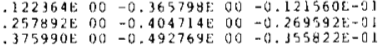

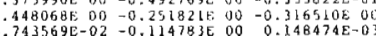
$268502 E-01-0.154864 E$ Dn $-0.3958228-0$ $\begin{aligned} .213394 \mathrm{E}-01 & -0.149864 \mathrm{E} \\ 00 & -0.320794 \mathrm{E}-02\end{aligned}$

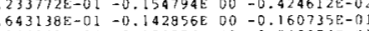

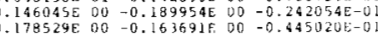
$209124800-0.181623 E$ E $00-0.4393526:-01$ $\begin{array}{rllll}0.199086 E & 00 & -0.198174 \mathrm{E} & 00 & -0.46048 \mathrm{BE}-01 \\ 0.264364 \mathrm{E} & 00 & -0.215782 \mathrm{E} & 00 & -0.624651 \mathrm{E}-01\end{array}$

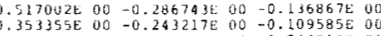
$.659753 \mathrm{E} 00-0.358898 \mathrm{E}$ : $00-0.743018 \mathrm{E}-0$ $.217755 \mathrm{E}$ 00 $-0.2767746 \mathrm{E}$ 00 $-0.222726 \mathrm{E}-01$ $0.142039 \mathrm{E} 00-0.246546 \mathrm{E} 00-0.151970 \mathrm{E}-01$

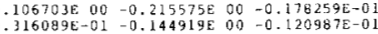
$\begin{array}{llll}0.636740 E-01 & -0.335358 E & 00 & -0.638777 \mathrm{E}-02\end{array}$ $.150905 \mathrm{E}$ 00 $-0.590106 \mathrm{E}_{\mathrm{E}} 00-0.109470 \mathrm{E}-0$

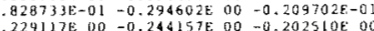
$0.555146 E=02-0.142072 \mathrm{E}$ ou $-0.1482398 \mathrm{E}-02$

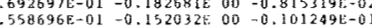
.1059E 00 -0.206170E 00 $00.111939 \mathrm{E}-0$

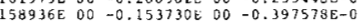

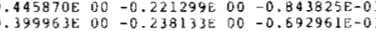
$.314606 \mathrm{E}$ 00 $-0.201304 \mathrm{E}$ 00 $-0.589147 \mathrm{E}-0$

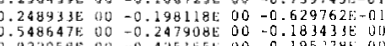
$0.891158 \mathrm{E} 00-0.331178 \mathrm{E} 00-0.125950 \mathrm{E}$ UO $\begin{array}{lllll}0.604844 E & 00 & -0.463778 E & 00 & -0.518292 \mathrm{E}-0 \\ 0.429608 \mathrm{E} & 00 & -0.404222 \mathrm{E} & 00 & -0.348880 \mathrm{~F}-0\end{array}$

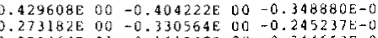

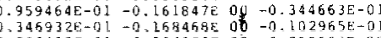
$0.893418 \mathrm{E}-01-0.504500 \mathrm{E}$ of $-0.755503 \mathrm{E}-02$ $0.142472 E$ EO $-0.943956 E$ O0 $-0.609980 \mathrm{E}-02$

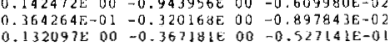
$.108542 \mathrm{E}$ 00 $-0.261358 \mathrm{E}$ U0 $-0.967951 \mathrm{E}-0$

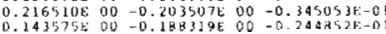
$.164634 \mathrm{E}_{0} 00-0.184818 \mathrm{E}$ no $-0.307641 \mathrm{E}-0$
$.253824 \mathrm{E} 00-0.198978 \mathrm{E} 00-0.494876 \mathrm{E}-0$

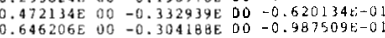

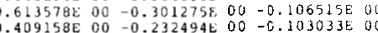
$0.427479 \mathrm{E} \quad 00-0.271676 \mathrm{E}$ O0 $-0.884852 \mathrm{E}-01$ $0.448347 \mathrm{E} \quad 0.0-0.307929 \mathrm{E} \quad 00-0.194272 \mathrm{E} \quad 00$

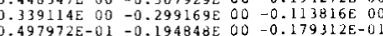
$371272 E-01-0.275904 E$
$000-0.985176 E-02$

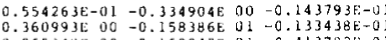
$.65348 \mathrm{E} 00-0.169047 \mathrm{E}$ ol $-0.413782 \mathrm{E}-0$

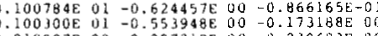
$0 . B 18907 E$ OO $-0.297312 E$ OO $-0.236683 E$ DO

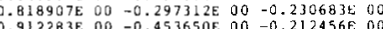

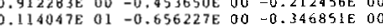

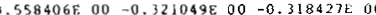
$0.117559 \mathrm{E} 00-0.249220 \mathrm{E}$ 00 $-0.411953 \mathrm{E}-01$ $0.831696 E-01-0.388581 E$ DU $-0.182800 E-01$

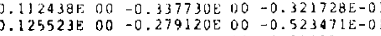


occurrence of earthquake surface wave magnitudes in Turkey, and contrasts results from adjacent seismicity cells of side $4^{\circ}$ throughout Turkey. The preferred statistics are Gumbel's third asymptotic distribution of extreme values. The Gumbel III distribution is uniquely specified by the three parameters $\omega, u$ and $\lambda$, and corresponding standard deviations and

Table A2. Parameters for seismic risk mapping in Turkey. Map 1 is derived from $M_{75}$; Map 2 from $M_{3}$ and Map 3 from $M$ ( $\left.P_{\mathrm{P}} \max \right)$.

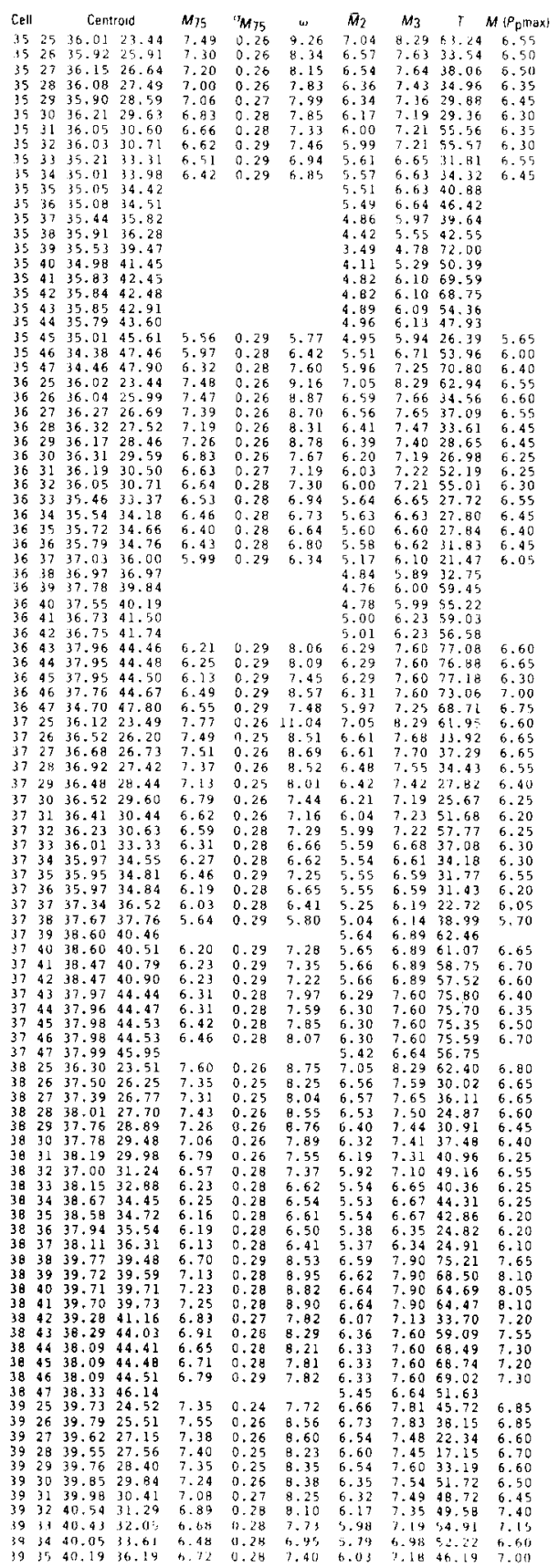

\begin{tabular}{|c|}
\hline Cell \\
\hline 39 \\
\hline 39 \\
\hline 39 \\
\hline 39 \\
\hline 39 \\
\hline 39 \\
\hline 39 \\
\hline 39 \\
\hline 29 \\
\hline 39 \\
\hline \\
\hline \\
\hline $\begin{array}{l}40 \\
40\end{array}$ \\
\hline $\begin{array}{l}40 \\
40\end{array}$ \\
\hline 40 \\
\hline 40 \\
\hline 40 \\
\hline 40 \\
\hline 40 \\
\hline 40 \\
\hline 40 \\
\hline 40 \\
\hline 40 \\
\hline \\
\hline \\
\hline 40 \\
\hline 40 \\
\hline 40 \\
\hline 40 \\
\hline 40 \\
\hline 40 \\
\hline 40 \\
\hline A l \\
\hline 41 \\
\hline 41 \\
\hline 41 \\
\hline 41 \\
\hline 41 \\
\hline 41 \\
\hline \\
\hline \\
\hline 41 \\
\hline di \\
\hline+1 \\
\hline 41 \\
\hline 4 \\
\hline \\
\hline 4 \\
\hline \\
\hline \\
\hline \\
\hline \\
\hline \\
\hline \\
\hline $\begin{array}{r}42 \\
42\end{array}$ \\
\hline \\
\hline 42 \\
\hline 42 \\
\hline \\
\hline 42 \\
\hline 4 \\
\hline 4 \\
\hline \\
\hline 4 \\
\hline 4 \\
\hline \\
\hline \\
\hline 4 \\
\hline \\
\hline \\
\hline \\
\hline 4 \\
\hline \\
\hline 4 \\
\hline \\
\hline \\
\hline 4 \\
\hline 43 \\
\hline $\begin{array}{l}43 \\
43\end{array}$ \\
\hline 43 \\
\hline \\
\hline \\
\hline 43 \\
\hline \\
\hline 4 \\
\hline 43 \\
\hline \\
\hline 4 \\
\hline 4 \\
\hline 4 \\
\hline 7 \\
\hline 4 \\
\hline 13 \\
\hline \\
\hline \\
\hline 4 \\
\hline 41 \\
\hline
\end{tabular}


covariances deduced from the covariance or error matrix obtained when Gumbel III is fitted to the available annual extreme earthquake magnitude data. Complete results of the Gumbellll parameters are listed in Table Al for all overlapping $4^{\circ}$ seismicity cells obtained at $1^{\circ}$ intervals throughout Turkey. These results can form the basic data set for any subsequent seismic risk estimation of frequency of earthquake occurrence in Turkey. The largest earthquake magnitude expected in any $75 \mathrm{yr}$ period is chosen as representative of seismic risk, and the results for $M_{75}$ in Table A2 form the basic data set from which Map 1 is the contoured interpretation. These $M_{75}$ and $\sigma_{M_{75}}$ result from the data of Table Al. Note that $M_{75}+\sigma_{M_{75}}$ may exceed the upper bound $\omega$. The complete results on which the strain energy and perceptibility interpretations of contour Maps 2 and 3 depend are also listed in Table A2. Although each seismicity cell of $4^{\circ}$ side is specified at its geographic centre, for contouring purposes the centroid obtained from the earthquake coordinates with energy weighting is used to specify the grid of risk parameters in all cases. 